\title{
Multi-technique comparison of troposphere zenith delays and gradients during CONT08
}

Kamil Teke (1,2), Johannes Böhm (1), Tobias Nilsson (1), Harald Schuh (1), Peter Steigenberger (3), Rolf Dach (4), Robert Heinkelmann (5), Pascal Willis (6,7), Rüdiger Haas (8), Susana GarcíaEspada (8,9), Thomas Hobiger (10), Ryuichi Ichikawa (11), Shingo Shimizu (12)

(1) Institute of Geodesy and Geophysics, Vienna University of Technology, Vienna, Austria. Email: johannes.boehm@tuwien.ac.at; kteke@mars.hg.tuwien.ac.at, tobias.nilsson@tuwien.ac.at, harald.schuh@tuwien.ac.at, phone: 00-43-1-588 01 12862, fax: 00-43-1588 0112896

(2) Geomatics Department, Hacettepe University, Ankara, Turkey.

(3) Institut für Astronomische und Physikalische Geodäsie, Technische Universität München, Arcisstraße 21, D-80333 München, Germany. Email: steigenberger@bv.tum.de

(4) Astronomical Institute, University of Bern, Switzerland. Email: rolf.dach@aiub.unibe.ch

(5) Deutsches Geodätisches Forschungsinstitut DGFI, Alfons-Goppel-Str. 11, 80539 München, Germany. Email: heinkelmann@dgfi.badw.de

(6) Institut Géographique National, Direction Technique, 2 avenue Pasteur, BP68, 94160 SaintMandé, France

(7) Institut de Physique du Globe de Paris (IPGP, Paris 7, CNRS), 35 rue Helène Brion, 75013 Paris, France. Email: willis@ipgp.fr

(8) Department of Radio and Space Science, Chalmers University of Technology, Onsala Space Observatory, SE-439 94 Onsala, Sweden. Email: rudiger.haas@chalmers.se

(9) Instituto Geografico Nacional, Apartado 148, E-19080 Yebes, Spain. Email: s.gespada@oan.es

(10) Space-Time Standards Group, National Institute of Information and Communications Technology (NICT), 4-2-1 Nukui-Kitamachi, Koganei,184-8795 Tokyo, Japan. Email: hobiger@nict.go.jp

(11) Space-Time Standards Group, Kashima Space Research Center, National Institute of Information and Communications Technology (NICT), 893-1 Hirai, Kashima, Ibaraki 314-0012, Japan.Email: richi@nict.go.jp

(12) National Research Institute for Earth Science and Disaster Prevention, 3-1 Tennodai, Tsukuba, 305-0006 Ibaraki, Japan. Email: shimizus@bosai.go.jp 
Abstract. CONT08 was a 15 days campaign of continuous VLBI (Very Long Baseline Interferometry) sessions during the second half of August 2008 carried out by the International VLBI Service for Geodesy and Astrometry (IVS). In this study, VLBI estimates of troposphere zenith total delays (ZTDs) and gradients during CONT08 were compared with those derived from observations with the Global Positioning System (GPS), Doppler Orbitography and Radiopositioning Integrated by Satellite (DORIS), and water vapor radiometers (WVRs) co-located with the VLBI radio telescopes. Similar geophysical models were used for the analysis of the space geodetic data, whereas the parameterization for the least-squares adjustment of the space geodetic techniques was optimized for each technique.. In addition to space geodetic techniques and WVRs, ZTDs and gradients from numerical weather models (NWMs) were used from the European Centre for Medium-Range Weather Forecasts (ECMWF) (all sites), the Japan Meteorological Agency (JMA) and Cloud Resolving Storm Simulator (CReSS) (Tsukuba), and the High Resolution Limited Area Model (HIRLAM) (European sites). Biases, standard deviations, and correlation coefficients were computed between the troposphere estimates of the various techniques for all eleven CONT08 co-located sites. ZTDs from space geodetic techniques generally agree at the sub-centimetre level during CONT08, and - as expected - the best agreement is found for intra-technique comparisons: between the Vienna VLBI Software and the combined IVS solutions as well as between the Center for Orbit Determination in Bern (CODE) solution and an IGS Kalman filter series; both intratechnique comparisons with standard deviations of about 3 to $6 \mathrm{~mm}$. The best inter space geodetic technique agreement of ZTDs during CONT08 is found between the combined IVS and the IGS solutions with a mean standard deviation of about $6 \mathrm{~mm}$ over all sites, whereas the agreement with numerical weather models is between 6 and $20 \mathrm{~mm}$. The standard deviations are generally larger at low latitude sites because of higher humidity, and the latter is also the reason why the standard deviations are larger at northern hemisphere stations during CONT08 in comparison to CONT02 which was observed in October 2002. The assessment of the troposphere gradients from the different techniques is not as clear because of different time intervals, different estimation properties, or different observables. However, the best inter-technique agreement is found between the IVS combined gradients and a GPS solutions with standard deviations between $0.2 \mathrm{~mm}$ and 0.7 $\mathrm{mm}$.

Keywords: space geodetic techniques, numerical weather models, troposphere zenith delays, horizontal troposphere gradients 


\section{Introduction}

Modelling the propagation of the electromagnetic microwave signals through the electrically neutral part of the atmosphere (in this paper referred to as troposphere) is of common interest for the space geodetic techniques, e.g., Very Long Baseline Interferometry (VLBI), Global Navigation Satellite Systems (GNSS) such as the Global Positioning System (GPS), or Doppler Orbitography and Radiopositioning Integrated by Satellite (DORIS). The troposphere causes an excess delay as well as the bending of the microwave signals along the path through the troposphere; the (slant) delay $(\Delta L)$ along the slant path $(s)$ between the station and the top of the troposphere $\left(H_{\text {trop }}\right)$ can be expressed as the integral over the sum of hydrostatic and wet refractivity $\left(N_{h, w}\right)$ :

$$
\Delta L=10^{-6} \int_{0}^{H_{\text {trop }}}\left[N_{h}(s)+N_{w}(s)\right] d s .
$$

Equation (1) can be decomposed into hydrostatic, wet, and gradient delays (Davis et al., 1993) as follows:

$$
\Delta L(\alpha, \varepsilon)=Z H D m_{h}(\varepsilon)+Z W D m_{w}(\varepsilon)+m_{h, w}(\varepsilon) \cot (\varepsilon)\left[G_{n} \cos (\alpha)+G_{e} \sin (\alpha)\right]
$$

where $\varepsilon$ is the elevation angle from local horizon, $\alpha$ the azimuth (angle from geodetic north), and ZHD the zenith hydrostatic delay, which can be computed from the total pressure and the station coordinates (Saastamoinen, 1972). $Z W D$ is the zenith wet delay, $m_{h}(\varepsilon)$ and $m_{w}(\varepsilon)$ are the hydrostatic and wet mapping functions (e.g., Marini, 1972; Niell, 1996; Böhm et al., 2006a), $G_{n}$ and $G_{e}$ are north and east troposphere gradients (MacMillan, 1995; Bar-Sever et al., 1998), respectively. The hydrostatic mapping function is accounting for the bending effect.

Troposphere delays are an important error source for space geodetic measurements. Uncertainties in the troposphere delay models propagate into all geodetic estimates, and in particular into the height component of the station positions (Herring, 1986; Davis et al., 1991) due to the high correlations between zenith delays and station heights. The influence of different mapping functions and cut-off elevation angles on geodetic parameters like station heights and baseline lengths has been investigated in several studies, e.g., Davis et al. (1985), Böhm and Schuh (2004), Böhm et al. (2006a, 2006b), Teke et al. (2007), Tesmer et al. (2007), or Steigenberger et al. (2007). Troposphere gradients describe the azimuthally asymmetric delays (Davis et al., 1993). In the analysis of VLBI and GPS observations, they are usually estimated since this improves the accuracy of geodetic estimates. Different studies have been carried out to develop and evaluate troposphere gradient models (e.g., Chen and Herring, 1997). According to MacMillan (1995), VLBI baseline length 
repeatabilities can be improved by up to $8 \mathrm{~mm}$ if gradients are estimated, thus gradients are very important for the realization of terrestrial reference frames (TRFs) (Böhm and Schuh, 2007) and celestial reference frames (CRFs) (MacMillan and Ma, 1997).

Various comparisons of troposphere parameters derived from space geodetic techniques and numerical weather models (NWMs) have been performed in order to assess the level of agreement. Behrend et al. (2000, 2002) compared the ZWDs derived from the non-hydrostatic numerical weather prediction (NWP) model (MM5) (Cucurull and Vandenberghe, 1999) and a hydrostatic NWP model (HIRLAM) (Cucurull et al., 2000) with the observational results of VLBI, GPS, and a water vapor radiometer (WVR), and they found good agreement for the European geodetic VLBI network during six observing sessions in 1999 in terms of biases, standard deviations, and correlations. Snajdrova et al. (2006) compared zenith total delays (ZTDs) from GPS, VLBI, DORIS, WVR (hydrostatic delays were added), and ECMWF during CONT02 (a 15 days continuous VLBI campaign in 2002) for co-located sites with VLBI antennas, and the agreement between ZTDs from GPS and VLBI was rather good (see Table 7); DORIS was fairly compatible with GPS and VLBI, but the agreement for WVR and ECMWF with ZTDs estimated from spacegeodetic techniques was rather low. To get detailed information on comparisons of troposphere parameters, readers are referred to, e.g. MacMillan and Ma (1994), Chen and Herring (1997), Emardson et al. (1998), Haas et al. (1999), Behrend et al. (2000, 2002), Cucurull et al. (2000), Gradinarsky et al. (2000), Niell et al. (2001), or Schuh and Böhm (2003).

In our study, the troposphere zenith total delays from VLBI, GPS, DORIS, and WVRs are also compared with those determined by ray-tracing through the profiles of various NWMs. A detailed description of all datasets can be found in Section 2. In Section 3 we compare the ZTDs and gradients in terms of biases, standard deviations, and correlations, and we provide some conclusions in Section 4.

\section{CONT08 co-located sites, techniques and solutions}

This section provides a general overview of the co-located sites during CONT08, the data types available, and it focuses on the details inherent to each technique. CONT08 was a special campaign of the International VLBI Service for Geodesy and Astrometry (IVS, Schlüter and Behrend, 2007), and it was a follow-on to similar campaigns (CONT94, CONT95, CONT96, CONT02, and CONT05). The aim of this campaign was to derive the highest quality geodetic results that VLBI currently can provide. It was a 15 days continuous VLBI observation campaign, carried out from 12 to 26 of August 2008 with eleven sites on five continents (Figure 1). Unlike previous CONT 
campaigns, the CONT08 sessions were observed from 0 UT to 24 UT, and observational gaps between the single sessions (30 min gaps in the case of CONT05) were avoided by performing the daily station interrupts at well-coordinated, sequential times for all stations in order not to introduce gaps in the estimated time series, e.g. of Earth orientation parameters (Schuh and Behrend, 2009).

Figure 1 IVS CONT08 stations.

For all eleven sites of CONT08, troposphere zenith delays and gradients are available from VLBI and GPS, and for three sites (Ny-Ålesund in Norway, Hartebeesthoek in The Republic of South Africa, and Kokee Park on Hawaii, U.S.A.) also troposphere estimates from DORIS are provided. Profiles through NWMs were used to compute zenith total delays and to estimate gradients. These NWMs are a global model from the European Centre for Medium-Range Weather Forecasts (ECMWF), a regional model by the Japan Meteorological Agency (JMA) for East Asia, a regional model from the Cloud Resolving Storm Simulator (CReSS) covering Japan, and HIRLAM, which is also a regional model for Europe. ZWDs from the measurements of WVRs are available at three sites during CONT08: Onsala in Sweden, Wettzell in Germany, and Tsukuba in Japan. When comparing ZTDs of different techniques, ZHDs computed from surface pressure values were added to the ZWDs of the WVRs and HIRLAM. In Table 1 the acronyms of GPS antennas, DORIS beacons, and WVR names at VLBI co-location sites are listed.

Table 1 Geodetic instruments co-located at the VLBI sites during the CONT08 campaign.

Table 2 shows the ITRF2005 (Altamimi et al., 2007) ellipsoidal heights of the reference points of VLBI, GPS, DORIS, and WVRs, as well as the GPS antenna reference point (ARP) eccentricity in the radial direction (the radial distance from the geodetic marker to the phase center of the GPS antenna). GPS ARP eccentricities in radial direction are added to the heights of the GPS reference points when calculating the troposphere ties (see Section 3.2). The approximate horizontal distances between co-located sites are listed in Table 2 to give an idea on how similar the troposphere above the geodetic instruments can be assumed.

Table 2 ITRF2005 ellipsoidal heights and approximate horizontal distances of the co-located VLBI, GPS, and DORIS antennas, and WVRs involved in CONT08.

At the end of this introduction it should be emphasized that all comparisons and validation tests carried out in this study provide important information with respect to the planned combination and integration of various observing techniques. In fact, such a multitude of different methods to 
simultaneously determine troposphere parameters from space geodetic techniques and other sources have never been available for comparison before. Thus, the data taken during the CONT08 campaign will greatly contribute to studies in the framework of the Global Geodetic Observing System (GGOS) (Rummel et al., 2005) of the International Association of Geodesy (IAG).

\subsection{Space geodetic solutions}

\subsubsection{VLBI-Vienna VLBI Software (VLBI-VieVS)}

For the analysis of the VLBI observations carried out during CONT08, the Vienna VLBI Software (VieVS, Böhm et al., 2010) was used. Neither any cut-off elevation angle nor any down weighting of low elevation observations was applied (in CONT08 no VLBI observation was taken below $5^{\circ}$ elevation). The zenith hydrostatic delays were determined from local surface pressure measurements (Saastamoinen 1972; Davis et al., 1985), whereas the zenith wet delays were estimated in the least-squares adjustment as piece-wise linear offsets at 30 minutes time intervals. In both cases - hydrostatic and wet - the Vienna Mapping Functions 1 (VMF1, Böhm et al., 2006a) were used. No-net-translation (NNT) and no-net-rotation (NNR) condition equations were introduced on the ITRF2005 (Altamimi et al., 2007) coordinates, except for the antenna Zelenchukskaya which is not available in ITRF2005. Source coordinates were fixed to ICRF2 (Fey et al., 2009), and atmospheric loading (Petrov and Boy 2004) as well as tidal ocean loading based on the ocean model FES2004 (Lyard et al., 2006) were introduced a priori. Nutation offsets were estimated once per day in addition to the IAU2000A model plus IERS 05 C04 values (Gambis 2004; Bizouard and Gambis 2009), and polar motion as well as the Earth's phase of rotation (UT1UTC) were estimated once per day in addition to the IERS 05 C04 values and the ocean tidal terms as recommended by the IERS Conventions 2003 (McCarthy and Petit 2004). The estimation interval was 30 minutes for the ZWDs and 120 minutes for troposphere gradients. Loose constraints for ZWDs (10 mm after 30 minutes $)$ and troposphere gradients $(0.17 \mathrm{~mm}$ after 120 minutes $)$ were introduced.

\subsubsection{VLBI-International VLBI Service for Geodesy and Astrometry (VLBI-IVS)}

Like previous IVS troposphere products (Heinkelmann et al., 2007), the combination of troposphere parameters during the 15 days CONT08 campaign is based on final ZTD and gradient time series by individual groups (and not carried out at the normal equation level). The VLBI-IVS series is a weighted linear combination of the estimates provided by ten IVS Analysis Centers (see Heinkelmann et al., this issue). It is important to note here that the solution with the Vienna VLBI Software (Section 2.1.1) was also part of the IVS combination which was carried out at Deutsches 
Geodätisches Forschungsinstitut. However, we want to keep both solutions in order to assess the difference between an individual and the combined solution compared to other techniques. Also, it has to be mentioned that the parameterization and the models are not homogeneous for all submissions that were used in the combination. After manual outlier exclusion, the weights for each IVS Analysis Center and parameter (zenith delays, horizontal gradients) were obtained by variance component estimation using the iterative algorithm of Förstner (1979) as outlined in Koch (1997). The details of the submissions, combination procedure and a quality assessment are presented by Heinkelmann et al. (this issue).

\subsubsection{DORIS- Institut Géographique National (DORIS-IGN)}

For the DORIS data analysis, the GIPSY-OASIS software package developed at JPL and modified at IGN (Willis et al., 2010b) was used. Instead of the results from the regular IGN solution (ignwd08) submitted to the International DORIS Service (IDS) (Willis et al., 2010c), a specific study was performed by using the VMF1 and also daily estimates (for test purposes in this specific study) of horizontal troposphere gradients, following some initial tests of consistency towards GPS (Willis et al., 2010a). A cut-off elevation angle of $10^{\circ}$ was used, as Jason-2 DORIS data were not considered yet in this investigation and as the older DORIS satellites do not provide a large amount of data below this elevation angle. Consequently, during CONT08, only 4 DORIS satellites were used (Envisat, SPOT-2, SPOT-4 and SPOT-5), all having a sun-synchronous and almost polar orbit. DORIS data were processed in daily batches using a filter approach. Zenith troposphere parameters were estimated at the start of passes, and only if the previous reset was not within 20 minutes (see Bock et al., 2010, for a more detailed discussion). This solution is as close as possible to the IERS Conventions 2003 (McCarthy and Petit, 2004), and it also includes the most recent improvement in DORIS data analysis, in particular in terms of solar radiation pressure modelling (Gobinddass et al., 2009a, 2009b) as well as in terms of atmospheric drag parameterization (Gobinddass et al., 2010). Station coordinates were fixed to their ign09d02 values. This frame is based on the ignwd08 time series, it provides coordinates and velocities for all stations, and it is aligned to ITRF2005 (Willis et al., 2010b). Discontinuities in station coordinates were also properly handled using information contained in DPOD2005 (Willis et al., 2009).

\subsubsection{GPS-International GNSS Service (GPS-IGS)}

This ZTD product of the IGS (Byun and Bar-Sever, 2009) was estimated by using the precise point positioning (PPP) technique as defined in Zumberge et al. (1997). The Earth orientation parameters, orbits, and clocks were fixed to the IGS final combined products. The analyses were carried out with the software GIPSY-OASIS for 24 hour data intervals (Webb and Zumberge, 1993). A cut-off 
elevation angle of $7^{\circ}$ was introduced, and the Niell mapping functions (hydrostatic and wet) (NMF; Niell, 1996) were used. A priori hydrostatic and wet delays were applied based on station altitude ( $2.3 \mathrm{~m}$ at sea level, and $0.1 \mathrm{~m}$, respectively). The estimated parameters were receiver clocks (modelled as white noise), station positions (constant), zenith wet delays (random walk with variance of $3 \mathrm{~cm} / \mathrm{h}$, loose) every 5 minutes, atmospheric gradients (random walk with variance of $0.3 \mathrm{~cm} / \mathrm{h}$, loose), and phase biases (white noise). The formal errors of the new ZTD product are about 1.5 to $5 \mathrm{~mm}$. However, they are biased by systematic errors in the combined GPS orbits and clocks, as concluded by Byun and Bar-Sever (2009).

\subsubsection{GPS-Center for Orbit Determination in Europe (GPS-CODE)}

The Center for Orbit Determination in Europe (CODE, Dach et al., 2009) is a cooperation of the Astronomical Institute of the University of Bern (AIUB), the Swiss Federal Office of Topography (swisstopo), the German Federal Agency for Cartography and Geodesy (BKG), and the Institut für Astronomische und Physikalische Geodäsie of the Technische Universität München (IAPG/TUM). CODE is one of the global IGS Analysis Centers. The solution used in this paper originated from the CODE contribution to the first IGS reprocessing campaign (Steigenberger et al., 2010). It is based on a global network of 244 GPS tracking stations processed with the current development version 5.1 of the Bernese GPS Software (Dach et al., 2007), and the following models were used: gridded VMF1 and ECMWF a priori delays, non-tidal atmospheric loading model of Petrov and Boy (2004) applied on the observation level, and S1/S2 atmospheric tidal model of Ray and Ponte (2003).

Daily normal equations were combined for the whole CONT08 time period to get one consistent solution for station coordinates, Earth rotation parameters, troposphere zenith delays and gradients. One set of station coordinates was estimated with an NNT condition of a subset of IGS05 stations w.r.t. the IGS05 reference frame. Troposphere zenith delays and gradients were represented by continuous piece-wise linear functions with a parameter spacing of 2 and 24 hours, respectively. An elevation cut-off angle of $3^{\circ}$ and an elevation-dependent weighting $\left(w=\sin ^{2} \varepsilon\right)$ were applied.

\subsection{Water Vapor Radiometer (WVR)}

A Water Vapor Radiometer (WVR) infers the wet troposphere delay from measurements of the power of the thermal radiation from the atmosphere at microwave frequencies. Typically two frequencies are used; one more sensitive to water vapor (typically a frequency close to the 22.2 $\mathrm{GHz}$ water vapor line) and one more sensitive to liquid water (usually around $30 \mathrm{GHz}$ ). By combining these measurements, the respective contributions from water vapor and liquid water to 
the observed powers can be determined. The water vapor part can then be used to estimate the wet troposphere delay (Elgered, 1993).

During CONT08 three WVRs were operated at VLBI sites: the Astrid radiometer at Onsala (Elgered and Jarlemark, 1998), as well as the Radiometrix radiometers at Wettzell and Tsukuba. The radiometers at Onsala and Wettzell were operated in sky mapping mode, thus providing measurements of the slant wet delays in several different directions. These were used in a leastsquares fit in order to estimate the ZWDs and the gradients, using an approach similar to what is presented by Davis et al. (1993). In the least-squares fit, the ZWDs and the gradients were modelled as piece-wise linear functions. The estimation intervals were $30 \mathrm{~min}$ for the ZWDs and 2 hours for the gradients, i.e. the same as for VLBI-VieVS. The Tsukuba radiometer only measured in the zenith direction, thus only ZWD estimates from this radiometer were available.

One problem with WVRs is, that they do not provide reliable results when it is raining. Consequently, all data from rainy periods have been removed (identified by the liquid water content being larger than $0.7 \mathrm{~mm}$ ). However, it should be noted that since the removal of rain observations was done a posteriori, the remaining observations could still be somewhat affected by rain since all observations were used for e.g. the tip-curve calibrations. Another problem is, that they cannot measure at low elevation angles $\left(<20^{\circ}\right)$ in order to avoid picking up radiation from the ground. Thus, the gradients estimated from the WVRs will be very sensitive to noise, since the effect of gradients is mostly seen for low elevation angles.

\subsection{Numerical Weather Models (NWMs)}

\subsubsection{European Centre for Medium-Range Weather Forecasts (ECMWF)}

Operational pressure level data with a 6 hour time resolution were used at 21 levels from $1000 \mathrm{hPa}$ up to $1 \mathrm{hPa}$ (extended up to $136 \mathrm{~km}$ with a normal temperature field) with information about the geopotential, temperature, and specific humidity. In particular, four vertical profiles with a horizontal resolution of $0.25^{\circ}$ around each station were retrieved and simply the closest profile was used for the determination of the zenith delay. The description of the algorithm for the numerical integration can be found in Böhm (2004; Appendix). For the calculation of north and east gradients, horizontal refractivity gradients were derived between the four profiles and again used for numerical integration (Böhm and Schuh, 2007). 


\subsubsection{High Resolution Limited-Area Model (HIRLAM)}

The High Resolution Limited-Area Model (HIRLAM) is a numerical weather model for short-range forecasting, that is used by several European national meteorological services (Undén et al., 2002). It is a limited area forecasting model that uses ECMWF as boundary conditions. Different spatial resolution is available, horizontally $22 \mathrm{~km}, 11 \mathrm{~km}$ or $5 \mathrm{~km}$, and vertically between 16 and 60 levels. The temporal resolution is 6 hours in analysis mode, and predictions are available, e.g. with 3 and 6 hours resolution.

HIRLAM files with $22 \mathrm{~km}$ horizontal resolution and 40 vertical levels and combined analysis and forecast data were used to achieve a temporal resolution of 3 hours. This was done by correcting the 3 hour forecast data by corrections based on a comparison of the 6 hour forecast data with the corresponding analysis data. So-called hybrid-level data of humidity and temperature together with surface pressure and geopotential data were extracted for the four nearest grid points around each station for each 6 hour epoch during CONT08. Based on these data vertical profiles of pressure, temperature and humidity were constructed for each station and finally vertical integration was used to calculate zenith wet delays.

\subsubsection{Japan Meteorological Agency-Kashima Ray-Tracing Tools (JMA-KARAT)}

At the National Institute of Information and Communications Technology (NICT) the so-called KAshima RAy-tracing Tools (KARAT, Hobiger et al., 2008a) have been developed, which allow to obtain troposphere slant delays in real-time. Such ray-traced delays can be used as corrections for space geodetic observations (Hobiger et al., 2008b) and remote sensing applications. The Japanese Meteorological Agency (JMA) provides a variety of weather models, whereas the meso-scale 4DVar model (Meso-scale Analysis Data, MANAL, JMA, 2002; Ishikawa, 2001) with its horizontal resolution of about $10 \mathrm{~km}$ is usually taken for KARAT processing. This model covers huge parts of the East Asian region, including Japan, Korea, Taiwan, and East China. The 3 hour time resolution of the datasets makes the appliance of this model for positioning applications feasible.

\subsubsection{Cloud Resolving Storm Simulator (CReSS)}

Other than regional numerical weather models, fine-mesh models allow to study smallest structures in the atmosphere and some models even try to resolve clouds. Thereby, the model space is limited to a few hundred kilometres, which requires some modifications of the ray-tracing code (Hobiger et al., 2010), in order to ensure that rays are not leaving the model domain laterally. Dedicated model runs of the Cloud Resolving Storm Simulator (CReSS; Tsuboki and Sakakibara, 2002) at the National Research Institute for Earth Science and Disaster Prevention (NIED) provided $1 \mathrm{~km}$ fine- 
mesh model data with a temporal resolution of one hour during the CONT08 period, which were used for the ray-tracing. Thereby, the CReSS model is embedded within the $10 \mathrm{~km}$ JMA MANAL field to ensure that rays at lower elevations are not cut off due to the spatial limitations of the finemesh model.

The gradients of JMA/KARAT and CReSS numerical weather model solutions were calculated as follows: The mean ray-traced slant delays, one for each elevation angle, were calculated from $3^{\circ}$ to $90^{\circ}$ elevation angle for the case of JMA/KARAT and $4^{\circ}$ to $90^{\circ}$ for the case of CReSS. I.e., for each elevation angle the mean values over the 360 ray-traced slant delays (every degree in azimuth) were determined, which were then subtracted from the individual ray-traced slant delays at all azimuths and elevation angles. The north and east gradients every 3 hours for JMA/KARAT and every hour for CReSS were estimated by a classical least-squares adjustment fitting the gradient model suggested by MacMillan (1995).

\section{Data analysis}

This section includes the analyses and comparisons of the estimated parameters by means of descriptive statistics. Before the comparisons "troposphere ties" were introduced with respect to a reference height, which was chosen as the height of the VLBI reference point.

\subsection{Agreement criteria for the comparisons}

In order to assess the agreement between the estimated troposphere ZTDs and gradients basic statistics were applied. We used mean biases of the difference vectors between time series, the standard deviations as well as the Pearson correlation coefficients. As statistical test for the correlation coefficients, p-values with a critical value of 0.05 were computed. Strictly speaking, the p-value is the probability of making a Type 1 error (the error of rejecting a null hypothesis when it is actually true) where a null hypothesis is formed with no correlation between two datasets (Schervish, 1996).

\subsection{Troposphere ties}

The atmosphere in the layer between two instruments causes biases of the troposphere ZTDs which can be called "troposphere ties". Troposphere tie corrections were introduced to account for the height differences between the antennas of geodetic techniques at the co-located sites before determining the difference vectors $(\Delta)$, and they were derived as the sum of the hydrostatic (Saastamoinen, 1972, 1973) and the wet part (Brunner and Rüeger, 1992), as shown in Equations (3) to (5). 
$p=p_{0}\left(1-\frac{\gamma\left(H-H_{0}\right)}{T_{0}}\right)^{\frac{g}{\gamma R_{L}}}$

$\Delta Z H D=\frac{0.0022768\left(p-p_{0}\right)}{1-0.00266 \cos \left(2 \varphi_{0}\right)-0.28 \times 10^{-6} H_{0}}$

$\Delta Z W D=\frac{-2.789 e_{0}}{T_{0}^{2}}\left(\frac{5383}{T_{0}}-0.7803\right) \gamma\left(H-H_{0}\right)$

$H_{0}$ denotes the reference height (in our case the height of the VLBI reference point) in meters. The parameters $e_{0}, p_{0}$, and $T_{0}$ are the water vapor pressure in $\mathrm{hPa}$, total pressure in $\mathrm{hPa}$, and temperature in Kelvin, at the reference height, and they are derived from data of the ECMWF; $H$ and $p$ are the height and total pressure at the co-located site. The other parameters are the average temperature lapse rate $\gamma=-0.0065 \mathrm{Km}^{-1}$, the gravity $\mathrm{g}$ in $\mathrm{ms}^{-2}$ at the site, and $R_{L} \approx 287.058 \mathrm{~m}^{2} \mathrm{~s}^{-}$ ${ }^{2} \mathrm{~K}^{-1}$ is the specific gas constant.

In Table 3, the height differences between VLBI, GPS, DORIS antennas as well as WVRs are shown. The troposphere ZTD ties were calculated at each common epoch from the Equations (3) to (5) based on the meteorological parameters $e_{0}, p_{0}$, and $T_{0}$ from the ECMWF, interpolated linearly to the ZTD epochs of the corresponding techniques. Since the variability of the ZTD ties is significant - especially for the sites where the weather is humid - we reduced ZTD ties calculated for each common epoch from the ZTDs of the techniques before comparisons. In Figure 2, the troposphere ties between the GPS antenna TSKB and the VLBI antenna TSUKUB32 during CONT08 are shown. Red and black dotted lines illustrate total and hydrostatic ties, respectively, and the negative sign of the ties is due to the fact that the lower GPS antenna TSKB has more troposphere above the station than the VLBI antenna TSUKUB32. As can be seen in Figure 2, the ZHD ties vary only slightly around the value of $-4.5 \mathrm{~mm}$ at Tsukuba within the 15 days, but after adding the ZWD ties, the ZTD ties have significantly more variability, which is due to the fact that the atmosphere at Tsukuba is very humid in August.

Figure 2 Troposphere ties between the GPS antenna TSKB and the VLBI antenna TSUKUB32 during CONT08, calculated for all common epochs. Red and black dotted lines illustrate total and hydrostatic ties, respectively.

In Table 3, the mean ZTD, ZHD, and ZWD ties of the whole CONT08 duration are shown. The ZHD ties of the WVRs are zero since the ZHDs from VLBI were used (Table 3).

The mean ZTD biases between the VLBI antennas and the DORIS beacons at Ny-Ålesund $\left(\mathrm{H}_{\mathrm{VLBI}}-\right.$ $\left.\mathrm{H}_{\text {DORIS }}=34.70 \mathrm{~m}\right)$ and at Hartebeesthoek $\left(\mathrm{H}_{\mathrm{VLBI}}-\mathrm{H}_{\text {DORIS }}=-143.88 \mathrm{~m}\right)$ were reduced to $0.79 \mathrm{~mm}$ 
(from $-9.98 \mathrm{~mm}$ ) and to $4.62 \mathrm{~mm}$ (from $41.80 \mathrm{~mm}$ ), respectively, after introducing the mean troposphere ties. At the IGS site HARB $\left(\mathrm{H}_{\mathrm{VLBI}}-\mathrm{H}_{\mathrm{GPS}}=-145.02 \mathrm{~m}\right)$ the mean ZTD bias of 37.52 $\mathrm{mm}$ was reduced to $0.14 \mathrm{~mm}$ after introducing the ZTD tie $(37.39 \mathrm{~mm})$, whereas at the DORIS colocated site at Kokee Park $\left(\mathrm{H}_{\mathrm{VLBI}}-\mathrm{H}_{\text {DORIS }}=9.62 \mathrm{~m}\right)$ the mean bias increased from $2.32 \mathrm{~mm}$ to 5.16 $\mathrm{mm}$ after introducing the mean troposphere tie $(-2.84 \mathrm{~mm})$; however, this difference is comparably small. It should also be mentioned here that the distances between VLBI antennas and the DORIS beacons are rather large so that the DORIS signals (in particular at $2 \mathrm{GHz}$ ) do not disturb the VLBI observations. This can also be a reason for the worse agreement.

Table 3 Height differences and troposphere ties between the co-located VLBI, GPS, and DORIS antennas, and the WVRs involved in CONT08.

\subsection{Data types and epochs for comparisons}

In order to ensure a predicative comparison similar geophysical models were used for the analyses of space geodetic data, whereas the parameterization for the least-squares adjustment of the space geodetic techniques was optimized for each solution. In Table 4, an overview of the solutions, types of the estimates, and intervals for both zenith delays and gradients are listed. GPS-IGS and HIRLAM solutions do not provide gradients. All gradients from the techniques except WVR are total gradients.

Table 4 Summary of the data used for the comparisons.

The total number of common epochs of ZTDs (first line) and of gradients (second line) between VieVS and the other techniques during CONT08 can be found in Table 5. The reliability of the mean biases, standard deviations, and correlations increases and the vulnerability to outliers decreases directly proportional with the total number of ZTDs and gradients available (degrees of freedom). Due to the small number of gradients provided by CODE and DORIS solutions (16 estimates at maximum for the whole 15 days duration) biases, standard deviations, and correlations involving these solutions have to be interpreted with care.

The estimates from DORIS correspond to distinct epochs of actual measurements during the DORIS satellite passes. For the whole CONT08 campaign, the DORIS station at Ny-Ålesund (SPJB) provided 243 ZTDs with a gap (no observation) every day between 2 to 5 UT. The DORIS station KOLB at KOKEE Park provided in total 82 ZTDs, and each day is observed in two separate intervals between 7 to 10 and 20 to 23 UT. HBMB at Hartebeesthoek provided in total 77 ZTDs in 
CONT08 observed between 6 to 10 and 19 to 22 UT. In a first step, the zenith delays from DORIS were linearly interpolated to adjacent 2 hour intervals at UT integer hours. This interpolation was only performed for those integer hours when the time differences between the last observation before and the first observation after the integer hours is less than 6 hours. This is not optimum for DORIS ZTDs, as DORIS data are scarce and DORIS troposphere solutions are then provided using some interpolation. Bock et al. (2010) did a reverse approach interpolating the dense GPS data to the epochs of the DORIS passes. This provides a more realistic estimation of the DORIS performances. However, in this study, the current capability of all techniques was tested, so it is important to know the performances of all techniques over the complete period of observations and not only during DORIS satellite passes.

Table 5 ZTDs (first line) and troposphere gradients (second line) common epochs of VieVS with the other techniques during CONT08.

\subsection{ZTD comparisons}

\subsubsection{Intra-technique comparisons of ZTDs}

The intra-technique biases at the co-located sites between VieVS and the IVS combined solution are between $-1.6 \mathrm{~mm}$ and $1.9 \mathrm{~mm}$ with standard deviations between $2.3 \mathrm{~mm}$ (Wettzell) and $5.7 \mathrm{~mm}$ (Zelenchukskaya). This is similar to what is found for the differences between the CODE and the IGS solution, where the standard deviations are between $2.4 \mathrm{~mm}$ (Hartebeesthoek, HRAO) and 4.9 $\mathrm{mm}$ (Medicina). The biases between the GPS solutions are slightly larger with values between -4.5 (Wettzell, WTZR) and 2.9 (Medicina) $\mathrm{mm}$, but it has to be clearly stated that the VieVS series is part of the IVS combined solution, whereas the IGS Kalman filter solution differs from the CODE solution in many aspects, e.g. PPP vs. network approach, NMF vs. VMF1, or different frames.

At Wettzell, we have IGS ZTD solutions for three different receivers from three different manufacturers which are only separated by a few meters and thus observe the same troposphere (WTZA, WTZJ, and WTZR). The mean biases between the ZTD series are $-1.1 \mathrm{~mm}$ (WTZA WTZJ) or smaller, and all standard deviations are at about $1.5 \mathrm{~mm}$, which is significantly smaller than the standard deviation between the IGS and the CODE solution for WTZR (3.4 mm). Similar results are found at Ny-Ålesund, where we have two solutions from CODE (NYAL and NYA1) with no bias and a standard deviation of $1.0 \mathrm{~mm}$. The standard deviation between the ZTDs at NYA1 between CODE and IGS is $2.7 \mathrm{~mm}$. This discrepancy shows that the choice of analysis strategies is critical for the estimation of ZTDs whereas the hardware (antenna, receiver) or effects like multipath or antenna phase center variations only add a smaller fraction to the total uncertainty 
of ZTDs. This is also confirmed by the fact that at many sites the standard deviations between IGS and CODE is nearly as large as the standard deviations between VLBI and GPS solutions.

At Tsukuba, the best agreement of two weather models is between JMA and CReSS. This can be expected because the high-resolution CReSS model is embedded in and initialized with the JMA model. On the other hand, this agreement is slightly worse than between ECMWF and HIRLAM for European stations, but it has to be mentioned, that the latter stations are not as humid as Tsukuba. More details about biases and standard deviations can be found in Table 6 and the electronic supplement.

In order to find out the amount of shared variances (degree of linear relationship) between the estimates/products of each pair of techniques, correlation coefficients were calculated. In Table 10, the correlations of gradients between VieVS and other solutions (and their p-values in parentheses) are shown. Correlation coefficients with $\mathrm{p}>0.05$ are assumed to be statistically insignificant and are written in italic. The intra-technique correlations of ZTDs between VieVS and the IVS combined solution are between 0.96 and 1.00, between CODE and the IGS solution between 0.99 and 1.00 , and between ECMWF and HIRLAM they range from 0.55 (Zelenchukskaya) to 0.96 (Ny-Ålesund, and Svetloe). The correlations between the weather models ECMWF, JMA, and CReSS at Tsukuba are at about 0.9 . More details on the correlations of gradients can be found in Table 10 and all correlations including ZTDs in the electronic supplement.

\subsubsection{Inter-technique comparisons of ZTDs}

As an example Figure 3 shows the ZTDs at Wettzell during CONT08. Inter-technique ZTD biases and standard deviations w.r.t. the VieVS and the CODE solutions can be found in Table 6 and the mean values are also shown in Figure 4. (Statistics about all combinations of sites and techniques are in the electronic supplement to this paper). The biases between different space geodetic techniques are mostly smaller than $5 \mathrm{~mm}$ after the application of troposphere ties, with the largest value remaining between the IVS combined and the CODE solution at Medicina (Italy) with 6.2 $\mathrm{mm}$. In terms of standard deviation, the best inter space geodetic technique agreement of ZTDs is found between the IVS combined solution and the IGS Kalman filter solution, in particular at NyÅlesund with $2.7 \mathrm{~mm}$. Slightly worse is the agreement between VieVS and the IGS Kalman filter solution, between CODE and the IVS combined solution, and between CODE and VieVS.

Generally, the median standard deviation of all sites between ZTDs from GPS and VLBI is about 4 to $5 \mathrm{~mm}$. The agreement of ZTDs from DORIS with those from GPS and VLBI is rather good at 
Ny-Ålesund with a standard deviation of about $6 \mathrm{~mm}$ (there is a large number of common epochs), but it is worse at Kokee Park and Hartebeesthoek with more than $12 \mathrm{~mm}$. Inter-technique correlations can be found in the electronic supplement, confirming the findings for the standard deviations.

Figure 3 Troposphere ZTDs of the co-located site Wettzell during CONT08.

As far as the standard deviation of ZTDs from WVRs w.r.t. those from space geodetic techniques is concerned, the best agreement can be found at Onsala with about $5 \mathrm{~mm}$. This is significantly better than for Wettzell $(\sim 11 \mathrm{~mm})$ or Tsukuba $(\sim 20 \mathrm{~mm})$. Also the biases of ZTDs from WVRs are larger at Tsukuba. It should be noted, that during CONT08 rainy weather mostly contaminates the measurements of the WVR (Robs) at Tsukuba although obvious outlier observations due to rain were eliminated.

The standard deviations of ZTDs from numerical weather models compared to ZTDs from space geodetic techniques are between $\sim 6 \mathrm{~mm}$ at Ny-Ålesund and $\sim 20 \mathrm{~mm}$ at Tsukuba. It seems that CReSS data is closer to the space geodetic results than the JMA (e.g. around August 19, see electronic supplement). The CReSS model sometimes has differences w.r.t. VLBI at 0 UT similar to the JMA model. This comes from the fact that the CReSS model is initialized with the JMA model and needs some time to settle to its own physics. From Table 6 and the electronic supplement no conclusions can be drawn whether ECMWF or HIRLAM agrees better with ZTDs from space geodetic techniques, because this varies w.r.t. station and solution.

As a general trend, the standard deviations of the ZTDs decrease with the latitude, i.e., the minimum standard deviations are at the site Ny-Ålesund. On the other hand, the low latitude sites like Kokee Park and Tsukuba have significantly larger standard deviations of ZTDs. All correlations between the ZTDs of different techniques are larger than 0.9 and statistically significant.

Table 6 Mean biases and standard deviations of the ZTD difference vectors between VLBI-VieVS and GPS-CODE with the other solutions for the co-located sites during CONT08. The zenith hydrostatic delays from VLBI were added to the zenith wet delays of WVR and HIRLAM.

Figure 4 Mean biases and standard deviations of all ZTDs during CONT08 w.r.t. VLBI-VieVS (bias: dark grey, std. dev.: light grey) and GPS-CODE (bias: dark red, std. dev.: light red). 


\subsubsection{Comparison with CONT02}

Comparing the level of agreement of ZTDs in this study (CONT08) with the findings for CONT02 by Snajdrova et al. (2006) the following conclusions can be drawn (see also Table 7): The biases between VLBI and GPS slightly decrease for CONT08. This might be due to a better agreement of underlying models like the terrestrial reference frames used for the analyses and improved troposphere ties. On the other hand the standard deviations between VLBI and GPS increase for all stations except Hartebeesthoek (South Africa). This is certainly caused by the fact that CONT08 was observed in August which corresponds to northern hemisphere summer, which is a more humid period for stations in the northern hemisphere compared to October when CONT02 was observed. A similar increase in standard deviations for CONT08 (except for Hartebeesthoek) can be found for the comparison of ZTDs between ECMWF and space geodetic techniques, probably caused by the same reason. On the other hand, there is a better agreement between DORIS and GPS/VLBI for CONT08, which is due to improved DORIS data processing for this investigation.

Table 7 Comparison of mean biases and standard deviations of the ZTD difference vectors from CONT02 (Snajdrova et al., 2006) and CONT08 (this study) for the common sites. At those sites, where more than one IGS antenna was situated the following antennas were used for the comparison: NYAL, WTZR, and HRAO.

\subsection{Troposphere gradients comparisons}

Unlike the ZTDs, there are not as many north and east gradient series from the individual techniques available for comparison. We do not have gradients from the IGS Kalman filter solution, nor do we have gradients from HIRLAM or the WVR at Tsukuba. It has to be stressed again, that the gradients from the WVRs at Wettzell and Onsala are wet-only gradients and do not contain hydrostatic parts. All other gradients are gradients of the total delays. Exemplarily, the troposphere east gradients at Onsala are shown in Figure 5 and the most important features of the gradient comparison can already be seen there: The best agreement of gradients is found between VieVS and the IVS combined series which was expected because VieVS is part of the IVS combination (Heinkelmann et al., this issue). There are no biases and the mean standard deviation is at the level of $0.3 \mathrm{~mm}$. (See also Tables 8 and 9 and the electronic supplement.) The gradients provided by CODE only have a daily resolution which makes the comparison difficult and vague: Whereas the gradients from VLBI describe the mean asymmetry over two hours, the gradients from GPS (CODE) are averaged over 24 hours. However, the general agreement of north and east gradients from the CODE solution with gradients from VLBI is quite good $(\sim 0.5 \mathrm{~mm})$. Only at Tsukuba and Kokee Park, standard deviations larger than $1 \mathrm{~mm}$ occur (see electronic supplement with plots for all stations). 
Figure 5 Troposphere east gradients of the co-located site Onsala during CONT08.

The standard deviations of DORIS gradients w.r.t. gradients from VieVS are rather large, in particular at Hartebeesthoek (South Africa) with $1.8 \mathrm{~mm}$ and $0.9 \mathrm{~mm}$ in the east and north direction, and at Kokee Park (Hawaii, U.S.A.) with $1.2 \mathrm{~mm}$ in east and $0.9 \mathrm{~mm}$ in north direction. It can also be noted here, that there is a large north gradient bias of $\sim 1 \mathrm{~mm}$ for the DORIS station at Hartebeesthoek with respect to VLBI. This could come from the fact that, at this high latitude, the tracks of the DORIS satellites (all sun-synchronous, as we did not use Jason-2) are mostly east-west oriented, i.e. perpendicular to the north gradient. Willis et al. (2010a) see a similar problem for the other stations (equatorial or mid-latitude), when the tracks are north-south oriented and the eastwest gradient is only loosely determined. However, since the standard deviation is of about the same size, this bias is not very significant.

There is a large standard deviation of more than $1 \mathrm{~mm}$ for the gradients from the WVR at Wettzell, which might be due to a tilting of the instrument (see station-wise plots with gradients in the electronic supplement). In general the wet gradients from WVRs are noisier because they are only derived from slant delays above $20^{\circ}$ elevation (Figure 5). On the other hand, the biases should be disregarded because they might be caused from the neglected hydrostatic part.

The best intra-NWM agreement of north and east gradients is found between JMA and CReSS, which could be expected because the CReSS model is initialized with the data from the larger JMA model. One has to keep in mind that the gradients from the weather model are a snap-shot of the troposphere at a certain epoch, whereas the gradients from the space geodetic techniques are averaged over a certain period, which is related to the way how the temporal resolution of the gradients is parameterized. The gradients from VLBI are estimated from very sparse spatial sampling, i.e. one direction at a given epoch. Scan lengths are between 20 seconds to a few minutes (depending on the source flux density) for CONT08 but there are also several minutes slew times between on-source times. Thus, VLBI scans the sky with only about 25 scans per hour.

In order to find out the amount of shared variances (degree of linear relationship) between the gradients of each pair of techniques, Pearson correlation coefficients were calculated. In Table 10, the correlations of gradients between VieVS and the other solutions (and their p-values in parentheses) are shown. Correlation coefficients with $\mathrm{p}>0.05$ are assumed to be statistically insignificant and are written in italic. The correlation coefficients of north and east gradients 
between VieVS and the IVS combined solutions are above 0.85 except for the east gradient at Hartebeesthoek (0.70), and all are significant. The correlation coefficients between the gradient estimates from VieVS and CODE are mostly below 0.7 and some of them are insignificant.

Table 8 Mean biases and standard deviations of the troposphere east gradient difference vectors between VLBI-VieVS and other solutions for the co-located sites during CONT08. All the gradients except those derived from WVR (wet gradients) are total gradients.

Table 9 Mean biases and standard deviations of the troposphere north gradient difference vectors between VLBI-VieVS and other solutions for the co-located sites during CONT08. All gradients except those derived from WVR (wet gradients) are total gradients.

Table 10 Correlation coefficients and their p-values between the estimates* of VLBI-VieVS and other solutions for the co-located sites during CONT08. Correlations written in italic are statistically insignificant $(\mathrm{p}>0.05)$. (* troposphere north gradients (first line) and east gradients (second line)).

\section{Conclusions}

The space geodetic techniques VLBI, GPS, and DORIS, including co-located WVRs and the use of NWMs (ECMWF, HIRLAM, KARAT, CReSS during CONT08) allowed to perform a comprehensive comparison of simultaneously determined troposphere parameters. Due to the lack of space not all of the results could be provided in this paper (the supplementary material can be accessed online). The comparisons done in this study are essential before starting with any combination attempt in the sense of GGOS, the Global Geodetic Observing System of the IAG.

These are the main findings of this study: Zenith total delay (ZTD) estimates of space geodetic techniques generally agree at the sub-centimetre level during CONT08. For ZTDs, the best agreement is found from the intra-technique comparisons between VieVS and the IVS combined solution as well as CODE and the IGS Kalman filter solution with median standard deviations of 3$4 \mathrm{~mm}$ and 4-5 mm, respectively. The best inter space geodetic technique agreement of ZTDs during CONT08 is slightly worse and it can be found between IVS and IGS with a median standard deviation of about $5 \mathrm{~mm}$ over all sites. Since the standard deviation between ZTDs for co-located GPS receivers from one solution (IGS at Wettzell, CODE at Ny-Ålesund) is at about 1.0 to $1.5 \mathrm{~mm}$ and the standard deviation between IGS and CODE is nearly as large as w.r.t. VLBI solutions, it can be argued that the choice of the analysis options adds a major part to the total uncertainty of ZTDs from GPS.

As far as the overall agreement of ZTDs is concerned between the techniques/solutions, two groups can be formed. GPS and VLBI form a group with the best agreement. The second group consists of the other models/techniques which are DORIS, ECMWF, HIRLAM, KARAT, CReSS, and WVR. 
Correlation coefficients of ZTDs are typically larger than 0.9 and all of the correlations are statistically significant.

There is a latitude- and season-dependence of the standard deviations between the techniques. The standard deviations generally decrease with increasing northern and southern latitudes, which is due to the lesser amount of humidity at higher latitudes. Additionally, the comparison with the results from the CONT02 campaign in October 2002 showed, that standard deviations are generally larger during CONT08, which was observed in August 2008. In particular observations at Tsukuba are affected by the humid conditions in August.

The best intra-technique agreement of north and east gradients are found between VieVS and the IVS combined solution, which was not surprising because VieVS was part of the IVS combination for CONT08. In general it has to be stressed, that the results of the comparison of gradients have to be used with care. Not only because of different time intervals but also due to basic differences in the observed quantities and setups, in the case of gradients the reader is rather referred to the station-wise plots in the electronic supplement than to the numbers in the tables.

Organizing regular inter-technique comparison campaigns with consistent analysis models dedicated to the investigation of the troposphere would help to improve the data w.r.t. the weaknesses of the individual space geodetic techniques (e.g. low degrees of freedom, inadequacy of gradient models) and the weaknesses of NWMs in terms of conventions on data assimilation, time and spatial resolution of the profiles, and the ray-tracing technique.

\section{Acknowledgements}

We use in this study the data provided by the International VLBI Service for Geodesy and Astrometry (IVS), the International GNSS Service (IGS), the International DORIS Service (IDS), the Center for Orbit Determination in Europe (CODE), the European Centre for Medium-Range Weather Forecast (ECMWF), the Japan Meteorological Agency (JMA), and the Swedish Meteorological and Hydrological Institute (SMHI), and the authors would like to thank all components of the aforementioned services. Part of this work was supported by Centre National d'Etudes Spatiales (CNES). This is IPGP contribution XXX. Thomas Hobiger and Ryuichi Ichikawa were supported by a Grant-in-Aid for Scientific Research (KAKENHI-21241043). 


\section{References}

Altamimi Z, Collilieux X, Legrand J, Garayt B, Boucher C (2007) ITRF2005, A new release of the International Terrestrial Reference Frame based on time series of station positions and Earth orientation parameters, J Geophys Res 112(B9):B09401, doi:10.1029/2007JB004949

Bar-Sever YE, Kroger PM, Borjesson JA (1998). Estimating horizontal gradients of tropospheric path delay with a single GPS receiver. J Geophys Res 103(B3):5019-5035

Behrend D, Cucurull L, Vila J, Haas R (2000) An inter-comparision study to estimate zenith wet delays using VLBI, GPS, and NWP models, Earth Planets Space 52:691-694

Behrend D, Haas R, Pino D, Gradinarsky LP, Keihm SJ, Schwarz W, Cucurull L, Rius A (2002) MM5 derived ZWDs compared to observational results from VLBI, GPS and WVR. Physics and Chemistry of the Earth 27:3301-3308

Bizouard C, Gambis D (2009) The combined solution C04 for Earth orientation parameters consistent with International Terrestrial Reference Frame. In: Drewes H (ed) Geodetic reference frames, IAG symp 134:265-270, doi:10.1007/978-3642-00860-3_41

Bock O, Willis P, Lacarra M, Bosser P (2010) An inter-comparison of zenith tropospheric delays derived from DORIS and GPS data, Adv Space Res, doi:10.1016/j.asr.2010.05.018 (in press)

Böhm J (2004) Troposphärische Laufzeitverzögerungen in der VLBI, Geowissenschaftliche Mitteilungen, Heft Nr. 68, Schriftenreihe der Studienrichtung Vermessung und Geoinformation, Technische Universität Wien, ISSN 1811-8380 (in German)

Böhm J, Schuh H (2004) Vienna mapping functions in VLBI analyses. Geophys Res Lett 31(1):L01603, doi:10.1029/2003GL018984

Böhm J, Schuh H (2007) Troposphere gradients from the ECMWF in VLBI analysis. J Geod, 81:403-408. doi: $10.1007 / \mathrm{s} 00190-007-0144-2$

Böhm J, Werl B, Schuh H (2006a) Troposphere mapping functions for GPS and very long baseline interferometry from European Center for Medium-Range Weather Forecasts operational analysis data. J Geophys Res 111:B02406. doi:10.129/2005JB003629

Böhm J, Niell AE, Tregoning P, Schuh H (2006b) Global Mapping Function (GMF): A new empirical mapping function based on data from numerical weather model data. Geophys Res Lett 33:L07304. doi:10.1029/2005GL025546

Böhm J, Schuh H (2007) Troposphere gradients from the ECMWF in VLBI analysis. J Geod, 81:403-408. doi: $10.1007 / \mathrm{s} 00190-007-0144-2$

Böhm J, Böhm S, Nilsson T, Pany A, Plank L, Spicakova H, Teke K, Schuh H (2010) The new Vienna VLBI Software VieVS. IAG Symposia Series, Buenos Aires 2010, in press

Brunner FK, Rüeger JM (1992) Theory of the local scale parameter method for EDM. Bulletin Géodésique 66:355-364

Byun SH, Bar-Server YE (2009) A new type of troposphere zenith path delay product of the international GNSS service. J Geod, 83 (3-4):1-7, doi: 10.1007/s00190-008-0288-8

Chen G, Herring TA (1997) Effects of atmospheric azimuthal asymmetry on the analysis from space geodetic data. J Geophys Res 102(B9):20489-20502, doi:10.1029/97JB01739

Cucurull L, Vandenberghe F (1999) Comparision of PW estimated from MM5 and GPS data, MM5 workshop '99, Boulder, Colorado, U.S.A

Cucurull L, Navascues B, Ruffini G, Elosegui P, Rius A, Vila J (2000) The use of GPS to validate NWP systems: the HIRLAM model. J Atmospheric and Oceanic Technology 17(6): 773-787

Dach R, Hugentobler U, Fridez P, Meindl M (ed.) (2007) Bernese GPS Software Version 5.0 Astronomical Institute, University of Bern 
Dach R, Brockmann E, Schaer S, Beutler G, Meindl M, Prange L, Bock H, Jäggi A, Ostini L (2009) GNSS processing at CODE: status report. J Geod, 83, 353-365, doi: 10.1007/s00190-008-0281-2

Davis JL, Herring TA, Shapiro II, Rogers AEE, Elgered G (1985) Geodesy by radio interferometry: effects of atmospheric modeling errors on estimates of baseline length. Radio Sci 20(6): 1593-1607

Davis JL, Herring TA, Shapiro II (1991) Effects of atmospheric modeling errors on determinations of baseline vectors from VLBI, J of Geophys Res 96(B1), 643-650

Davis JL, Elgered G, Niell AE, Kuehn CE (1993) Ground-based measurements of gradients in the "wet" radio refractivity of air. Radio Sci 28(6):1003-1018

Elgered G (1993) Tropospheric radio path delay from ground-based microwave radiometry. In: JanssenM(Ed)Atmospheric remote sensing by microwave radiometry.Wiley, NewYork, pp 215-258

Elgered G, Jarlemark POJ (1998) Ground-based microwave radiometry and long-term observations of atmospheric water vapor. Radio Sci 33(3):707-717

Emardson TR, Elgered G, Johansson JM (1998) Three months of continuous monitoring of atmospheric water vapor with a network of Global Positioning System receivers. J. Geophys. Res., 103(D2), 1807-1820, doi:10.1029/97JD03015

Fey A, Gordon D, Jacobs CS (2009) The Second Realization of the International Celestial Reference Frame by Very Long Baseline Interferometry, IERS Technical Note; 35, Frankfurt am Main: Verlag des Bundesamts für Kartographie und Geodäsie, 204 p., ISBN 3-89888-918-6

Förstner W (1979) Ein Verfahren zur Schätzung von Varianz- und Kovarianzkomponenten. Allg. Vermess. Nachr, $11-$ $12: 446-453$ (in German)

Gambis D (2004) Monitoring Earth orientation using space geodetic techniques, State-of-the-art and prospective, J Geod, 78(4-5):295-303, doi:10.1007/s00190-004-0394-1

Gobinddass ML, Willis P, Sibthorpe A, Zelensky NP, Lemoine FG, Ries JC, Ferland R, Bar-Sever YE (2009a) Improving DORIS geocenter time series using an empirical rescaling of solar radiation pressure models. Adv Space res 44(11):1279-1287, doi: 10.1016/j.asr.2009.08.004

Gobinddass ML, Willis P, de Viron O, Sibthorpe AJ, Zelensky N, Ries JC, Ferland R, Bar-Sever YE, Diament M (2009b) Systematic biases in DORIS-derived geocenter time series related to solar radiation pressure mis-modelling, J Geod, 83(9):849-858, doi: 10.1007/s00190-009-0303-8

Gobinddass ML, Willis P, Menvielle M, Diament M (2010) Refining DORIS atmospheric drag in preparation of ITRF2008. Adv Space Res doi:10.1016/j.asr.2010.04.004

Gradinarsky LP, Haas R, Elgered G, Johansson JM (2000) Wet path delay and delay gradients inferred from microwave radiometer, GPS and VLBI observations. Earth Planets Space 52(10):695-698

Haas R, Gradinarsky LP, Johansson JM, Elgered G (1999) The atmospheric propagation delay: a common error source for collocated space techniques of VLBI and GPS. In: Proceedings of International Workshop "Geod. Meas. Coll. Spac. Tech. Earth" (GEMSTONE). Koganei, Tokyo, pp 230-234

Heinkelmann R, Böhm J, Schuh H, Bolotin S, Engelhardt G, MacMillan DS, Negusini M, Skurikhina E, Tesmer V, Titov O (2007) Combination of long time series of troposphere zenith delays observed by VLBI. J Geod, 81:483-501, doi:10.1007/s00190-007-0147-z

Heinkelmann R, Böhm J, Bolotin S, Engelhardt G, Haas R, MacMillan DS, Negusini M, Schuh H, Skurikhina E, Titov O. Analysis and model noise assessment of VLBI derived tropospheric parameters during CONT08. J Geod, this issue.

Herring TA (1986) Precision of vertical estimates from very long baseline interferometry, J Geophys Res., 91(B9), 9177-9182, doi:10.1029/JB091iB09p09177

Hobiger T, Ichikawa R, Koyama Y, Kondo T (2008a), Fast and accurate ray-tracing algorithms for real-time space geodetic applications using numerical weather models, J Geophys Res 113:D20302, doi:10.1029/2008JD010503 
Hobiger T, Ichikawa R, Takasu T, Koyama Y, Kondo T (2008b), Ray-traced troposphere slant delays for precise point positioning, Earth Planets Space, 60(5), e1-e4

Hobiger T, Shimada S, Shimizu S, Ichikawa R, Koyama Y, Kondo T (2010), Improving GPS positioning estimates during extreme weather situations by the help of fine-mesh numerical weather models. J Atmosph Solar-Terrestr Phys 72(2-3):262-270, doi:10.1016/j.jastp.2009.11.018

Ishikawa Y(2001), Development of a mesoscale 4-dimensional variational data assimilation (4D-Var) system at JMA, Proceedings of the 81st Annual Meeting of the AMS: Precipitation Extremes: Prediction, Impacts and Responses, P2.45

JMA (2002) Outline of the operational numerical weather prediction at the Japanese Meteorological Agency, 158pp

Koch KR (1997) Parameterschätzung und Hypothesentests, 3rd edn. Dümmler, Bonn, p 368

Lyard F, Lefevre F, Lettelier T, Francis O (2006) Modelling the global ocean tides, Modern insightths from FES2004, Ocean Dyn 56(6):394-415

MacMillan DS, Ma C (1994) Evaluation of very long baseline interferometry atmospheric modeling improvements. J Geophys Res 99(B1):637-651. doi:10.1029/93JB02162

MacMillan DS (1995) Atmospheric gradients from very long baseline interferometry observations. Geophys Res Lett 22(9):1041-1044, doi:10.1029/95GL00887

MacMillan DS, Ma C (1997) Atmospheric gradients and the VLBI terrestrial and celestial reference frames. Geophys Res Lett 24(4):453-456, doi: 10.1029/97GL00143

Marini JW (1972) Correction of satellite tracking data for an arbitrary tropospheric profile. Radio Sci 7(2),223-231

McCarthy D and Petit G (2004) (Eds) IERS Conventions 2003, IERS Techn. Note 32, Verlag des Bundesamts für Kartogr. und Geod., Frankfurt am Main, Germany

Niell AE (1996) Global mapping functions for the atmosphere delay at radio wavelengths. J Geophys Res 101(B2):3227-3246, doi:10.1029/95JB03048

Niell AE, Coster AJ, Solheim FS, Mendes VB, Toor PC, Langley RB, Upham CA (2001) Comparison of measurements of atmospheric wet delay by radiosonde, water vapor radiometer, GPS, and VLBI. J Atmos Oceanic Technol 18:830850

Petrov L, Boy JP (2004) Study of the atmospheric pressure loading signal in Very Long Baseline Interferometry observations, J Geophys Res 109(B3):B03405, doi:10.1029/2003JB002500

Ray RD, Ponte RM (2003) Barometric tides from ECMWF operational analyses. Ann Geophys, 21:1897-1910

Rummel R, Rothacher M, Beutler G (2005) Integrated Global Geodetic Observing System (IGGOS)-science rationale, Journal of Geodynamics, 40(4-5):357-362, doi: 10.1016/j.jog.2005.06.003

Saastamoinen J (1972) Atmospheric correction for the troposphere and stratosphere in radio ranging of satellites. The use of artificial satellites for geodesy, Geophys. Monogr. Ser. 15, Amer. Geophys. Union, 274-251

Saastamoinen J (1973) Contribution to the theory of atmospheric refraction (in three parts). Bull Geod 105-107: 279$298,383-397,13-34$

Schervish, MJ (1996) P Values: What They Are and What They Are Not. The American Statistician, 50(3): 203-206, doi: $10.2307 / 2684655$

Schlüter W, Behrend D (2007) The International VLBI Service for Geodesy and Astrometry (IVS): current capabilities and future prospects, J Geod, 81(6-8): 379-387, doi: 10.1007/s00190-006-0131-Z

Schuh H, Böhm J (2003) Status Report of the IVS pilot project-tropospheric parameters. In: Vandenberg NR, Baver KD (eds) International VLBI service for geodesy and astrometry 2002 annual report. NASA/TP-2003-211619. Goddard Space Flight Center, Maryland 
Schuh H, Behrend D (2009) International VLBI Service for Geodesy and Astrometry (IVS). In: Drewes H, Hornik H (eds) Report of the International Association of Geodesy 2007-2009 - Travaux de 1'Association Internationale de Géodésie 2007-2009, 36: 297-306

Snajdrova K, Böhm J, Willis P, Haas R, Schuh H (2006) Multi-technique comparison of tropospheric zenith delays derived during the CONT02 campaign, J Geod, 79:613-623. doi: 10.1007/s00190-005-0010-Z

Steigenberger P, Tesmer V, Krügel M, Thaller D, Schmid R, Vey S, Rothacher M (2007) Comparisons of homogeneously reprocessed GPS and VLBI long time-series of troposphere zenith delays and gradients. J Geod, 81(68):503-514, doi: 10.1007/s00190-006-0124-y

Steigenberger P, Hugentobler U, Lutz S, Dach R (2010) CODE Contribution to the IGS Reprocessing, Springer-Verlag

Tesmer V, Böhm J, Heinkelmann R, Schuh H (2007) Effect of different tropospheric mapping functions on the TRF, CRF and position time-series estimated from VLBI. J of Geod, 81:409-421. doi: 10.2007/s00190-006-0126-9

Teke K, Böhm J, Schuh H (2007) Baseline Length Repeatability and Vertical point position accuracy of VLBI CONT05 Sessions for Different Mapping Functions and Cut off Angles. European Geosciences Union General Assembly, Vienna, Austria

Tsuboki K, Sakakibara A (2002) Large-scale parallel computing of Cloud Resolving Storm Simulator, High Performance Computing, 243-259, doi:10.1007/3-540-47847-7_21

Undén P, Rontu L, Järvinen H, Lynch P, Calvo J, Cats G, Cuxart J, Eerola K, Fortelius C, Garcia-Moya J A, Jones C, Lenderlink G, McDonald A, McGrath R, Navascues B, Woetman Nielsen N, Ødegaard V, Rodriguez E, Rummukainen M, Rõõm R, Sattler K, Hansen Sass B, Savijärvi H, Wichers Schreur B, Sigg R, The H, Tijm A (2002) HIRLAM-5 Scientific documentation, Swedish Meteorological and Hyrdological Institute, Norrköping, 144 pages

Webb FH, Zumberge JF (1993) An introduction to GIPSY/ OASIS-II. JPL, Publication D-11088, Pasadena, CA

Willis P, Ries JC, Zelensky NP, Soudarin L, Fagard H, Pavlis EC, Lemoine FG (2009) DPOD2005, Realization of a DORIS terrestrial reference frame for precise orbit determination, Adv Space Res 44(5):535-54

Willis P, Bar-Sever YE, Bock O (2010a) Estimating horizontal tropospheric gradients in DORIS data processing, IAG Symp

Willis P, Boucher C, Fagard H, Garayt B, Gobinddass ML (2010b) Contributions of the French Institut Géographique National (IGN) to the International DORIS Service, Adv Space Res 45(12):1470-1480

Willis P, Ferrage P, Lemoine FG, Noll CE, Noomen R, Otten M, Ries JC, Rothacher M, Soudarin L, Tavernier G, Valette JJ (2010c) The International DORIS Service, Toward maturity, Adv Space Res 45(12):1408-1420

Zumberge JF, Heflin MB, Jefferson DC, Watkins MM, Web FH (1997) Precise point positioning for the efficient and robust analysis of GPS data from large networks. J Geophys Res 102:5005-5017 
Table 1 Geodetic instruments co-located at the VLBI sites during the CONT08 campaign.

\begin{tabular}{llcl}
\hline VLBI station & $\begin{array}{l}\text { IGS acronym and GPS } \\
\text { Solutions }\end{array}$ & IDS acronym & WVR name (site) \\
\hline Ny-Ålesund & NYA1 (CODE + IGS) & SPJB & - \\
& NYAL (CODE only) & & \\
Svetloe & SVTL (CODE + IGS) & - & - \\
Onsala & ONSA (CODE + IGS) & - & ASTRID \\
Wettzell & WTZR (CODE + IGS) & - & RADIOMETRIX \\
& WTZA (IGS only) & & \\
Medicina & WTZJ (IGS only) & & \\
Zelenchukskaya & ZEDI (CODE + IGS) & - & - \\
Westford & WES2 (CODE + IGS) & - & - \\
Tsukuba & TSKB (CODE only) & - & ROBS \\
& TSK2 (IGS only) & & \\
Kokee Park & KOKB (CODE + IGS) & KOLB & - \\
Hartebeesthoek & HRAO (CODE + IGS) & HBMB & - \\
& HARB (CODE only) & & \\
Tigo Concepcion & CONZ (CODE + IGS) & - & - \\
\hline
\end{tabular}


Table 2 ITRF2005 ellipsoidal heights and approximate horizontal distances of the co-located VLBI, GPS, and DORIS antennas, and WVRs involved in CONT08.

\begin{tabular}{|c|c|c|c|c|c|c|c|}
\hline $\begin{array}{l}\text { VLBI Station } \\
\text { (order w.r.t. lat.) }\end{array}$ & Country & $\begin{array}{l}\text { VLBI } \\
\text { height } \\
\text { (m) }\end{array}$ & $\begin{array}{l}\text { GPS phase center height }(\mathrm{m}) \\
\text { (reference point height }+ \text { up } \\
\text { eccentricity**) }\end{array}$ & $\begin{array}{l}\text { WVR } \\
\text { height } \\
(\mathrm{m})\end{array}$ & $\begin{array}{l}\text { DORIS height } \\
\text { (m) }\end{array}$ & $\begin{array}{l}\text { VLBI-DORIS } \\
\text { approximate } \\
\text { horizontal } \\
\text { distance }(\mathrm{m})\end{array}$ & $\begin{array}{l}\text { VLBI-GPS } \\
\text { approximate } \\
\text { horizontal } \\
\text { distance (m) }\end{array}$ \\
\hline Ny-Ålesund & Norway & 87.30 & $\begin{array}{l}84.18+0.00\left({ }^{1}\right) \\
78.45+5.22\left({ }^{2}\right)\end{array}$ & - & 52.60 (SPJB) & 1475 (SPJB) & $\begin{array}{l}106\left(\begin{array}{l}1 \\
)\end{array}\right. \\
112\left({ }^{2}\right)\end{array}$ \\
\hline Svetloe & Russia & 86.01 & $77.13 *+0.03$ & - & - & - & 82 \\
\hline Onsala60 & Sweden & 59.28 & $45.56+1.00$ & $\begin{array}{l}\sim 46.57 \\
(\text { ASTRID) }\end{array}$ & - & - & 78 \\
\hline Wettzell & Germany & 669.13 & $\begin{array}{l}666.03+0.07\left({ }^{3}\right) \\
665.92^{*}+0.08\left(^{4}\right) \\
665.91 *+0.07\left(^{5}\right)\end{array}$ & $\sim 667.56$ & - & - & $\begin{array}{l}139\left({ }^{3}\right) \\
140\left({ }^{4}\right) \\
137\left({ }^{5}\right)\end{array}$ \\
\hline Medicina & Italy & 67.17 & $50.04+0.00$ & - & - & - & 60 \\
\hline Zelenchukskaya & Russia & $1175.43 *$ & $1167.27+0.05$ & - & - & - & 65 \\
\hline Westford & USA & 86.77 & $85.02+0.00$ & - & - & - & 58 \\
\hline Tsukuba & Japan & 84.72 & $\begin{array}{l}67.25+0.00\left(^{6}\right) \\
70.35^{*}+0.00\left(^{7}\right)\end{array}$ & $\begin{array}{l}25.20 \\
\text { (ROBS) }\end{array}$ & - & - & $\begin{array}{l}302\left({ }^{6}\right) \\
306\left({ }^{7}\right)\end{array}$ \\
\hline Kokee Park & USA & 1176.60 & $1167.37+0.06$ & - & 1166.98 (KOLB) & 398 (KOLB) & 45 \\
\hline Hartebeesthoek & $\begin{array}{l}\text { South } \\
\text { Africa }\end{array}$ & $1416.12 *$ & $\begin{array}{l}1414.16+0.08\left({ }^{8}\right) \\
1558.09+3.05\left({ }^{9}\right)\end{array}$ & - & $1560.00(\mathrm{HBMB}) *$ & 2239 (HBMB) & $\begin{array}{l}164\left({ }^{8}\right) \\
2212\left({ }^{9}\right)\end{array}$ \\
\hline Tigo Concepcion & Chile & 170.95 & $180.69+0.06$ & - & - & - & 120 \\
\hline
\end{tabular}

$\left({ }^{1}\right)$ NYA1,$\left({ }^{2}\right)$ NYAL,$\left({ }^{3}\right)$ WTZR,$\left({ }^{4}\right)$ WTZJ,$\left(^{5}\right)$ WTZA, $\left({ }^{6}\right)$ TSKB,$\left({ }^{7}\right)$ TSK2, $\left({ }^{8}\right)$ HRAO, $\left({ }^{9}\right)$ HARB.

* Heights taken from the log file of the stations because not available in ITRF2005.

** Antenna reference point eccentricities are provided in the station log files at the IGS web site. 
Table 3 Height differences and troposphere ties between the co-located VLBI, GPS, and DORIS antennas, and the WVRs involved in CONT08.

\begin{tabular}{|c|c|c|c|c|c|c|}
\hline VLBI Station & $\begin{array}{l}\text { VLBI-GPS } \\
\text { height } \\
\text { difference } \\
(\mathrm{m})\end{array}$ & $\begin{array}{l}\text { Mean GPS } \\
\text { troposphere ties } \\
\mathrm{ZTD}=\mathrm{ZHD}+\mathrm{ZWD} \\
(\mathrm{mm})\end{array}$ & $\begin{array}{l}\text { VLBI-DORIS } \\
\text { height } \\
\text { difference } \\
(\mathrm{m})\end{array}$ & $\begin{array}{l}\text { Mean DORIS } \\
\text { troposphere ties } \\
\mathrm{ZTD}=\mathrm{ZHD}+\mathrm{ZWD} \\
(\mathrm{mm})\end{array}$ & $\begin{array}{l}\text { VLBI-WVR } \\
\text { height } \\
\text { difference } \\
(\mathrm{m})\end{array}$ & $\begin{array}{l}\text { Mean WVR } \\
\text { troposphere ties } \\
\mathrm{ZTD}=\mathrm{ZHD}+\mathrm{ZWD} \\
(\mathrm{mm})\end{array}$ \\
\hline Ny-Ålesund & $\begin{array}{l}3.12\left({ }^{1}\right) \\
3.63\left(^{2}\right)\end{array}$ & $\begin{aligned}-0.97 & =-0.88+(-0.09) \\
-1.13 & =-1.02+(-0.11)\end{aligned}$ & 34.70 & $-10.77=-9.78+(-0.99)$ & - & - \\
\hline Svetloe & 8.85 & $-2.92=-2.38+(-0.54)$ & - & - & - & - \\
\hline Onsala60 & 12.72 & $-4.16=-3.43+(-0.73)$ & - & - & $\sim 12.71$ & $-0.73=0.00+(-0.73)$ \\
\hline Wettzell & $\begin{array}{l}3.03\left({ }^{3}\right) \\
3.13\left(\left(^{4}\right)\right. \\
3.15\left(^{5}\right)\end{array}$ & $\begin{aligned}-0.94 & =-0.79+(-0.15) \\
-0.97 & =-0.82+(-0.15) \\
-0.97 & =-0.82+(-0.16)\end{aligned}$ & - & - & $\sim 1.57$ & $-0.08=0.00+(-0.08)$ \\
\hline Medicina & 17.13 & $-5.52=-4.51+(-1.01)$ & - & - & - & - \\
\hline Zelenchukskaya & 8.11 & $-2.35=-1.91+(-0.44)$ & - & - & - & - \\
\hline Westford & 1.75 & $-0.56=-0.46+(-0.10)$ & - & - & - & - \\
\hline Tsukuba & $\begin{array}{l}17.47\left({ }^{6}\right) \\
14.37\left(^{7}\right)\end{array}$ & $\begin{array}{l}-6.11=-4.58+(-1.52) \\
-5.02=-3.77+(-1.25)\end{array}$ & - & - & 59.52 & $-5.30=0.00+(-5.30)$ \\
\hline Kokee Park & 9.17 & $-2.72=-2.21+(-0.52)$ & 9.62 & $-2.84=-2.30+(-0.54)$ & - & - \\
\hline Hartebeesthoek & $\begin{array}{l}1.88\left({ }^{8}\right) \\
-145.02\left({ }^{9}\right)\end{array}$ & $\begin{array}{l}-0.51=-0.46+(-0.05) \\
37.39=33.40+3.99\end{array}$ & -143.88 & $37.18=33.19+(3.99)$ & - & - \\
\hline Tigo Concepcion & -9.80 & $3.07=2.66+0.40$ & - & - & - & - \\
\hline
\end{tabular}

(1) NYA1, $\left({ }^{2}\right)$ NYAL,$\left({ }^{3}\right)$ WTZR, $\left({ }^{4}\right)$ WTZJ, $\left({ }^{5}\right)$ WTZA, $\left({ }^{6}\right)$ TSKB, $\left({ }^{7}\right)$ TSK2, $\left({ }^{8}\right)$ HRAO, $\left({ }^{9}\right)$ HARB. 
Table 4 Summary of the data used for the comparisons.

\begin{tabular}{|c|c|c|c|}
\hline Technique & $\begin{array}{l}\text { Zenith total/wet } \\
\text { delay }\end{array}$ & $\begin{array}{l}\text { Estimation interval } \\
\text { of zenith delay }\end{array}$ & $\begin{array}{l}\text { Estimation interval } \\
\text { of gradients }\end{array}$ \\
\hline VLBI-VieVS & ZWD, ZTD & 30 minutes & 2 hours (total gradients) \\
\hline VLBI-IVS & ZWD, ZTD & 1 hour & 1 hour (total gradients) \\
\hline GPS/IGS & ZTD & 5 minutes & - \\
\hline GPS/CODE & ZTD & 2 hours & 1 day (total gradients) \\
\hline DORIS/IGN & ZTD & $\begin{array}{l}\text { per satellite pass (but not all), } \\
\text { using time constraints between passes }\end{array}$ & 1 day (total gradients) \\
\hline WVR & ZWD & 30 minutes & 2 hours (wet gradients) \\
\hline ECMWF & ZWD, ZTD & 6 hours & 6 hours (total gradients) \\
\hline JMA/KARAT & ZTD & 3 hours & 3 hours (total gradients) \\
\hline CreSS & ZTD & 1 hour & 1 hour (total gradients) \\
\hline HIRLAM & ZWD & 3 hours & - \\
\hline
\end{tabular}

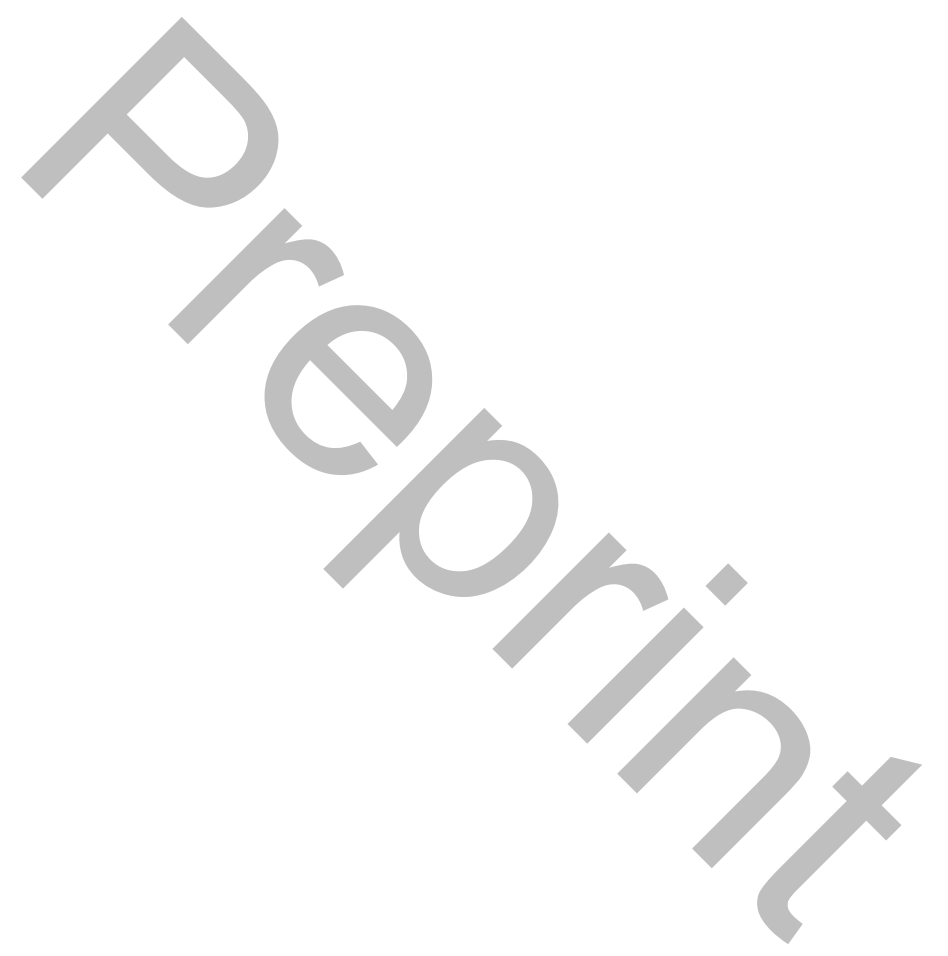


Table 5 ZTDs (first line) and troposphere gradients (second line) common epochs of VieVS with the other techniques during CONT08.

\begin{tabular}{|c|c|c|c|c|c|c|c|c|c|}
\hline & IVS & IGS & CODE & IGN & WVR & ECMWF & HIRLAM & KARAT & CReSS \\
\hline \multirow[t]{2}{*}{ Ny-Ålesund } & 357 & $714\left(^{1}\right)$ & $180\left(^{1}\right)$ & 149 & - & 60 & 120 & - & - \\
\hline & 179 & - & $16\left(^{1}\right)$ & 15 & - & 60 & - & - & - \\
\hline \multirow[t]{2}{*}{ Svetloe } & 360 & 672 & 181 & - & - & 60 & 121 & - & - \\
\hline & 180 & - & 16 & - & - & 60 & - & - & - \\
\hline \multirow[t]{2}{*}{ Onsala60 } & 360 & 623 & 181 & - & 593 & 60 & 121 & - & - \\
\hline & 180 & - & 16 & - & 181 & 60 & - & - & - \\
\hline \multirow[t]{2}{*}{ Wettzell } & 360 & $\begin{array}{l}662\left({ }^{3}\right) \\
616\left(^{4}\right) \\
670\left(^{5}\right)\end{array}$ & $181\left(^{3}\right)$ & - & 548 & 60 & 121 & - & - \\
\hline & 180 & - & $16\left(^{3}\right)$ & - & 169 & 60 & - & - & - \\
\hline \multirow[t]{2}{*}{ Medicina } & 360 & 720 & 181 & - & - & 60 & 121 & - & - \\
\hline & 180 & - & 16 & - & - & 60 & - & - & - \\
\hline \multirow[t]{2}{*}{ Zelenchukskaya } & 326 & 552 & - & - & - & 55 & 110 & - & - \\
\hline & 163 & - & - & - & - & 55 & - & - & - \\
\hline \multirow[t]{2}{*}{ Westford } & 360 & 672 & 169 & - & - & 60 & - & - & - \\
\hline & 180 & - & 15 & - & - & 60 & - & - & - \\
\hline \multirow[t]{2}{*}{ Tsukuba } & 360 & $719\left(^{7}\right)$ & $181\left(^{6}\right)$ & - & 560 & 60 & - & 121 & 361 \\
\hline & 180 & - & $16\left({ }^{6}\right)$ & - & - & 60 & - & 61 & 181 \\
\hline \multirow[t]{2}{*}{ Kokee Park } & 360 & 720 & 181 & 66 & - & 60 & - & - & - \\
\hline & 180 & - & 16 & 15 & - & 60 & - & - & - \\
\hline \multirow[t]{2}{*}{ Hartebeesthoek } & 360 & $720\left({ }^{8}\right)$ & $181\left(^{8}\right)$ & 60 & - & 60 & - & - & - \\
\hline & 180 & - & $16\left(^{8}\right)$ & 15 & - & 60 & - & - & - \\
\hline \multirow[t]{2}{*}{ Tigo Concepcion } & 242 & 192 & 122 & - & - & 39 & - & - & - \\
\hline & 121 & - & 11 & - & - & 39 & - & - & - \\
\hline
\end{tabular}

$\left({ }^{1}\right)$ NYA1, $\left({ }^{2}\right)$ NYAL,$\left({ }^{3}\right)$ WTZR, $\left({ }^{4}\right)$ WTZJ, $\left({ }^{5}\right)$ WTZA, $\left({ }^{6}\right)$ TSKB,$\left({ }^{7}\right)$ TSK2, $\left({ }^{8}\right)$ HRAO, $\left({ }^{9}\right)$ HARB. 
Table 6 Mean biases and standard deviations of the ZTD difference vectors between VLBI-VieVS and GPS-CODE with the other solutions for the co-located sites during CONT08. The zenith hydrostatic delays from VLBI were added to the zenith wet delays of WVR and HIRLAM.

\begin{tabular}{|c|c|c|c|c|c|c|c|c|c|c|c|}
\hline & Ny-Ålesund & Svetloe & Onsala & Wettzell & Medicina & Zelenchukskaya & Westford & Tsukuba & Kokee Park & Hartebeesthoek & Tigo Concepcion \\
\hline$\overline{\text { VLBI/VieVS-VLBI/IVS }}$ & $-1.6 \pm 2.8$ & $0.3 \pm 3.3$ & $-0.4 \pm 2.6$ & $-0.4 \pm 2.3$ & $-1.0 \pm 4.7$ & $1.9 \pm 5.7$ & $-0.2 \pm 3.1$ & $-0.1 \pm 4.8$ & $-0.2 \pm 4.7$ & $-0.7 \pm 3.2$ & $-1.0 \pm 4.0$ \\
\hline VLBI/VieVS-GPS/IGS & $-2.0 \pm 3.9(\mathrm{NYA} 1)$ & $1.2 \pm 5.5$ & $1.0 \pm 4.5$ & $2.2 \pm 4.1$ (WTZR) & $2.3 \pm 7.0$ & $2.8 \pm 11.1$ & $-4.5 \pm 6.1$ & $-0.6 \pm 11.1(\mathrm{TSK} 2)$ & $0.8 \pm 8.3$ & $-0.2 \pm 4.7(\mathrm{HRAO})$ & $-4.0 \pm 5.1$ \\
\hline VLBI/VieVS-GPS/CODE & $0.0 \pm 3.9($ NYAL $)$ & $1.0 \pm 6.1$ & $3.1 \pm 5.0$ & $-2.1 \pm 4.6(\mathrm{WTZR})$ & $5.1 \pm 7.9$ & - & $-3.7 \pm 6.4$ & $1.4 \pm 11.6(\mathrm{TSKB})$ & $1.9 \pm 9.5$ & $0.1 \pm 5.2(\mathrm{HRAO})$ & $-4.5 \pm 5.0$ \\
\hline VLBI/VieVS-DORIS/IGN & $0.8 \pm 6.4$ & - & - & - & - & - & - & - & $5.2 \pm 14.7$ & $4.6 \pm 12.7$ & - \\
\hline VLBI/VieVS-WVR & - & - & $-0.4 \pm 5.1$ & $-14.3 \pm 10.3$ & - & - & - & $-24.8 \pm 22.2$ & - & - & - \\
\hline VLBI/VieVS-ECMWF & $-3.4 \pm 6.5$ & $0.9 \pm 10.9$ & $3.4 \pm 11.2$ & $-2.1 \pm 11.8$ & $-2.1 \pm 19.8$ & $4.1 \pm 20.0$ & $-3.8 \pm 16.6$ & $-0.3 \pm 20.2$ & $2.9 \pm 18.1$ & $3.0 \pm 8.4$ & $0.9 \pm 11.2$ \\
\hline VLBI/VieVS-JMA/KARAT & - & - & - & - & - & - & - & $7.8 \pm 25.7$ & - & - & - \\
\hline VLBI/VieVS-CreSS & - & - & - & - & - & - & - & $6.0 \pm 20.0$ & - & - & - \\
\hline VLBI/VieVS-HIRLAM & $0.6 \pm 11.1$ & $0.8 \pm 16.2$ & $6.4 \pm 11.0$ & $2.5=$ & $2.4 \pm 18.0$ & $6.0 \pm 20.7$ & - & - & - & - & - \\
\hline GPS/CODE -VLBI/IVS & $-1.4 \pm 2.9(\mathrm{NYA} 1)$ & $-0.7 \pm 5.1$ & $-3.3 \pm 4.5$ & $1.8 \pm 4.2($ WTZR) & $-6.2 \pm 8.7$ & - & $3.7 \pm 5.5$ & $-1.5 \pm 9.7$ & $-2.0 \pm 7.3$ & $-0.9 \pm 4.0(\mathrm{HRAO})$ & $2.4 \pm 7.3$ \\
\hline GPS/CODE-GPS/IGS & $-1.9 \pm 2.7$ (NYA1) & $0.5 \pm 4.1$ & $-2.0 \pm 4.0$ & $4.5 \pm 3.4(\mathrm{WT} 2$ & $-2.9 \pm 4.9$ & - & $-0.3 \pm 4.7$ & - & $-1.0 \pm 4.5$ & $-0.2 \pm 2.4(\mathrm{HRAO})$ & $1.2 \pm 2.6$ \\
\hline GPS/CODE-DORIS/IGN & $0.7 \pm 5.4(\mathrm{NYA} 1)$ & - & - & - & & - & - & - & $3.2 \pm 13.0$ & $4.1 \pm 13.1$ (HRAO) & - \\
\hline GPS/CODE-WVR & - & - & $-3.1 \pm 5.7$ & $-12.5 \pm 11.6(\mathrm{WTZR})$ & & - & - & $-26.1 \pm 20.2$ & - & - & - \\
\hline GPS/CODE-ECMWF & $-3.4 \pm 5.9$ (NYA1) & $0.1 \pm 10.6$ & $-0.1 \pm 11.1$ & $-0.8 \pm 11.5(\mathrm{WTZR})$ & $-8.8 \pm 18.4$ & - & $-1.7 \pm 14.7$ & $0.2 \pm 20.6$ & $1.9 \pm 16.5$ & $2.0 \pm 8.3(\mathrm{HRAO})$ & $4.4 \pm 9.7$ \\
\hline GPS/CODE-JMA/KARAT & - & - & - & - & & 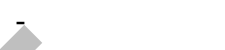 & - & $7.1 \pm 20.6$ & - & - & - \\
\hline GPS/CODE-CreSS & - & - & - & - & & & - & $5.3 \pm 18.9$ & - & - & - \\
\hline GPS/CODE-HIRLAM & $1.2 \pm 10.2$ (NYA1) & $0.4 \pm 14.6$ & $3.6 \pm 9.6$ & $2.5 \pm 9.4$ (WTZR) & $-3.2 \pm 16.7$ & - & - & - & - & - & - \\
\hline
\end{tabular}


Table 7 Comparison of mean biases and standard deviations of the ZTDs difference vectors from CONT02 (Snajdrova et al., 2006) and CONT08 (this study) for the common sites. (The IGS antennas are NYAL, WTZR, and HRAO at sites with more than one antenna.)

$\begin{array}{ccccc}\text { Ny-Ålesund } & \text { Onsala60 } & \text { Wettzell } & \text { Westford } & \text { Kokee Park Hartebeesthoek }\end{array}$

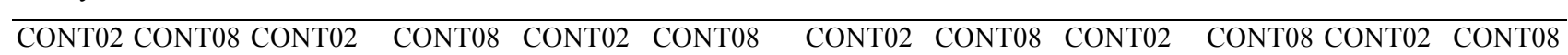

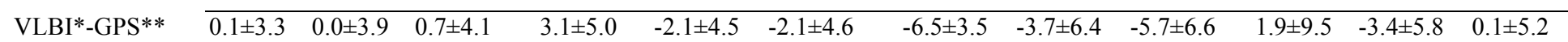

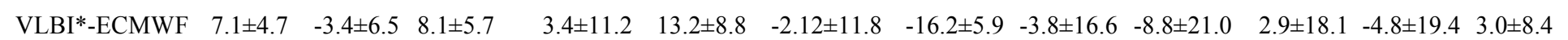

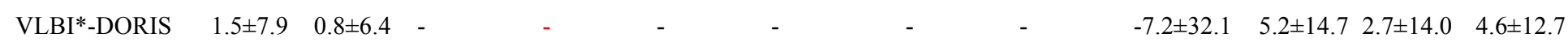

$\begin{array}{lllllllllll}\text { VLBI*-WVR } & - & - & - & -2.8 \pm 6.7 & -0.4 \pm 5.1 & -17.2 \pm 9.0 & -14.3 \pm 10.33 & - & - & -\end{array}$

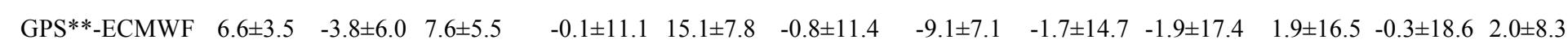

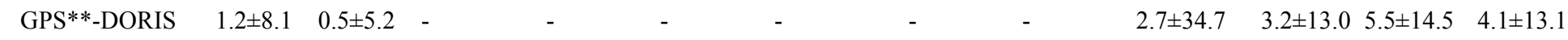

$\begin{array}{lllllllllll}\text { GPS**-WVR } & - & - & -3.7 \pm 5.4 & -3.1 \pm 5.7 & -14.7 \pm 8.1 & -12.5 \pm 11.6 & - & - & - & -\end{array}$

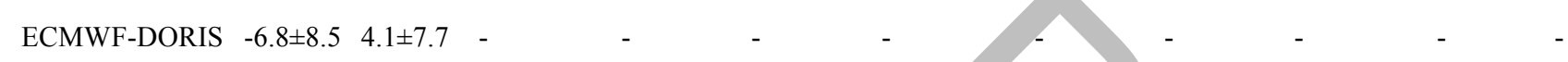

$\begin{array}{lllllllllll}\text { ECMWF-WVR } & - & - & -11.7 \pm 10.2 & -3.1 \pm 10.9 & -26.2 \pm 7.5 & -11.9 \pm 15.6 & - & - & - & -\end{array}$

* VieVS solution

** CODE solution 
Table 8 Mean biases and standard deviations of the troposphere east gradient difference vectors between VLBI/VieVS and other solutions for the co-located sites during CONT08. All the gradients except those derived from WVR (wet gradients) are total gradients.

\begin{tabular}{|c|c|c|c|c|c|c|c|c|c|c|c|}
\hline & Ny-Ålesund & Svetloe & Onsala & Wettzell & Medicina & Zelenchukskaya & Westford & Tsukuba & Kokee Park & Hartebeesthoek & Tigo Concepcion \\
\hline VLBI/VieVS-VLBI/IVS & $0.0 \pm 0.2$ & $0.0 \pm 0.2$ & $0.0 \pm 0.2$ & $0.0 \pm 0.2$ & $0.0 \pm 0.2$ & $0.1 \pm 0.4$ & $0.0 \pm 0.2$ & $0.1 \pm 0.4$ & $0.0 \pm 0.2$ & $-0.1 \pm 0.3$ & $0.1 \pm 0.3$ \\
\hline VLBI/VieVS-GPS/CODE & $0.2 \pm 0.5$ (NYA 1$)$ & $0.2 \pm 0.5$ & $-0.1 \pm 0.5$ & $-0.3 \pm 0.6(\mathrm{WTZR})$ & $0.0 \pm 0.5$ & - & $-0.4 \pm 0.8$ & $0.2 \pm 1.1(\mathrm{TSKB})$ & $0.1 \pm 0.7$ & $0.0 \pm 0.5(\mathrm{HRAO})$ & $0.1 \pm 0.8$ \\
\hline VLBI/VieVS-DORIS/IGN & $0.2 \pm 0.7$ & - & - & - & - & - & - & - & $-0.2 \pm 1.2$ & $0.2 \pm 1.8$ & - \\
\hline VLBI/VieVS-WVR & - & - & $0.3 \pm 0.8$ & $0.0 \pm 1.3$ & - & - & - & - & - & - & - \\
\hline VLBI/VieVS-ECMWF & $0.0 \pm 0.4$ & $0.2 \pm 0.5$ & $0.0 \pm 0.4$ & $-0.1 \pm 0.6$ & $0.0 \pm 0.5$ & $0.1 \pm 0.7$ & $0.0 \pm 0.5$ & $-0.3 \pm 0.9$ & $-0.2 \pm 0.6$ & $0.1 \pm 0.4$ & $0.2 \pm 0.5$ \\
\hline VLBI/VieVS-JMA/KARAT & - & - & - & - & - & - & - & $0.1 \pm 0.9$ & - & - & - \\
\hline VLBI/VieVS-CreSS & - & - & - & - & - & - & - & $0.1 \pm 0.9$ & - & - & - \\
\hline
\end{tabular}

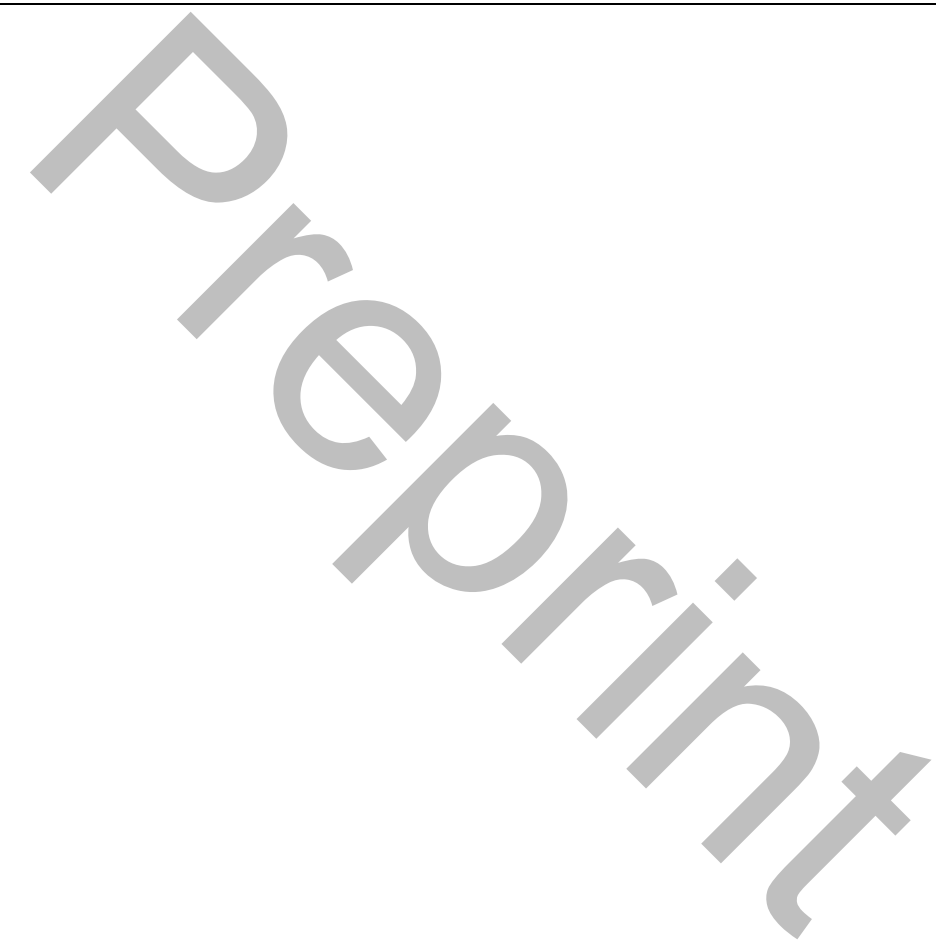


Table 9 Mean biases and standard deviations of the troposphere north gradient difference vectors between VLBI-VieVS and other solutions for the co-located sites during CONT08. All gradients except those derived from WVR (wet gradients) are total gradients.

\begin{tabular}{|c|c|c|c|c|c|c|c|c|c|c|c|}
\hline & Ny-Ålesund & Svetloe & Onsala & Wettzell & Medicina & Zelenchukskaya & Westford & Tsukuba & Kokee Park & Hartebeesthoek & Tigo Concepcion \\
\hline VLBI/VieVS-VLBI/IVS & $0.0 \pm 0.2$ & $0.0 \pm 0.2$ & $0.0 \pm 0.2$ & $0.0 \pm 0.2$ & $0.0 \pm 0.3$ & $-0.2 \pm 0.4$ & $0.0 \pm 0.2$ & $0.0 \pm 0.4$ & $0.0 \pm 0.3$ & $0.3 \pm 0.4$ & $0.0 \pm 0.3$ \\
\hline VLBI/VieVS-GPS/CODE & $0.0 \pm 0.4(\mathrm{NYA} 1)$ & $-0.2 \pm 0.5$ & $0.3 \pm 0.6$ & $-0.1 \pm 0.4($ WTZR $)$ & $-0.1 \pm 0.8$ & - & $-0.5 \pm 0.5$ & $0.3 \pm 1.1(\mathrm{TSKB})$ & $0.2 \pm 1.1$ & $0.5 \pm 0.5$ (HRAO) & $0.3 \pm 0.5$ \\
\hline VLBI/VieVS- DORIS/IGN & $0.4 \pm 0.7$ & - & - & - & - & - & - & - & $-0.3 \pm 1.2$ & $1.2 \pm 0.9$ & - \\
\hline VLBI/VieVS-WVR & - & - & $-0.4 \pm 0.8$ & $-0.6 \pm 1.1$ & - & - & - & - & - & - & - \\
\hline VLBI/VieVS-ECMWF & $0.0 \pm 0.4$ & $-0.1 \pm 0.5$ & $0.0 \pm 0.5$ & $-0.1 \pm 0.4$ & $0.0 \pm 0.8$ & $-0.7 \pm 1.0$ & $0.0 \pm 0.4$ & $0.5 \pm 1.0$ & $-0.2 \pm 0.8$ & $0.3 \pm 0.6$ & $0.3 \pm 0.5$ \\
\hline VLBI/VieVS-JMA/KARAT & - & - & - & - & - & - & - & $0.2 \pm 1.0$ & - & - & - \\
\hline VLBI/VieVS-CreSS & - & - & - & - & - & - & - & $0.2 \pm 1.0$ & - & - & - \\
\hline
\end{tabular}

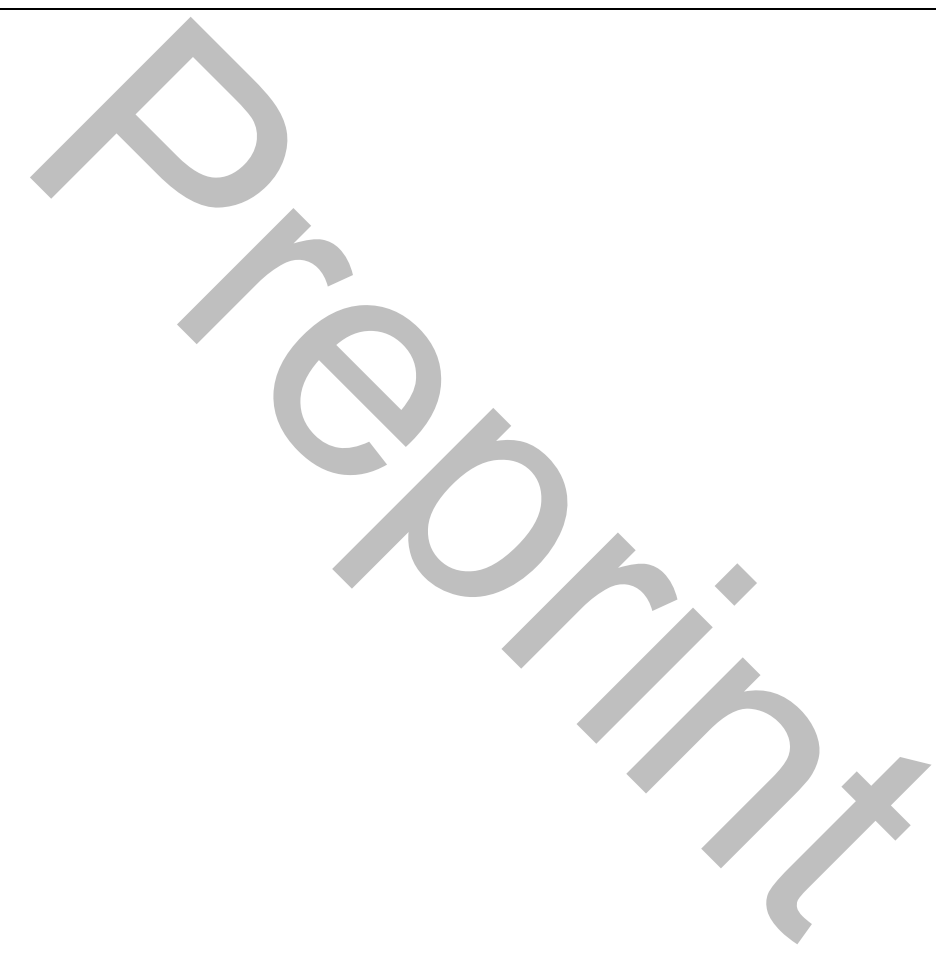




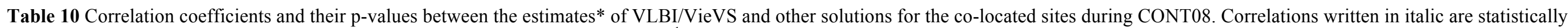
insignificant $(\mathrm{p}>0.05) .\left(*\right.$ troposphere north gradients $\left(1^{\text {st }}\right.$ line $)$ and east gradients $\left.\left(2^{\text {nd }} l i n e\right)\right)$.

\begin{tabular}{|c|c|c|c|c|c|c|c|c|c|c|c|}
\hline & Ny-Ålesund & Svetloe & Onsala & Wettzell & Medicina & Zelenchukskaya & Westford & Tsukuba & Kokee Park & Hartebeesthoek & Tigo Concepcion \\
\hline \multirow[t]{2}{*}{ VLBI/VieVS-VLBI/IVS } & $0.93(0.00)$ & $0.94(0.00)$ & $0.93(0.00)$ & $0.89(0.00)$ & $0.91(0.00)$ & $0.86(0.00)$ & $0.93(0.00)$ & $0.92(0.00)$ & $0.89(0.00)$ & $0.87(0.00)$ & $0.86(0.00)$ \\
\hline & $0.93(0.00)$ & $0.89(0.00)$ & $0.93(0.00)$ & $0.95(0.00)$ & $0.88(0.00)$ & $0.92(0.00)$ & $0.87(0.00)$ & $0.93(0.00)$ & $0.91(0.00)$ & $0.70(0.00)$ & $0.85(0.00)$ \\
\hline \multirow[t]{2}{*}{ VLBI/VieVS-GPS/CODE } & $0.74(0.00)$ NYA1 & $0.75(0.00)$ & $0.69(0.00)$ & $0.39(0.13) W T Z R$ & $0.54(0.03)$ & - & $0.64(0.01)$ & $0.49(0.05)$ & $-0.19(0.48)$ & $0.68(0.00)$ HRAO & $0.58(0.06)$ \\
\hline & $0.57(0.02)$ NYA1 & $0.34(0.20)$ & $0.70(0.00)$ & $0.80(0.00)$ WTZR & $0.56(0.02)$ & - & $0.25(0.34)$ & $0.55(0.03)$ & $0.34(0.20)$ & $0.25(0.35) \mathrm{HRAO}$ & $0.23(0.50)$ \\
\hline \multirow{2}{*}{ VLBI/VieVS-DORIS/IGN } & $0.19(0.49)$ & - & - & - & - & - & - & - & $-0.06(0.83)$ & $0.16(0.57)$ & - \\
\hline & $-0.16(0.56)$ & - & - & - & - & - & - & - & $0.41(0.13)$ & $0.40(0.14)$ & - \\
\hline \multirow[t]{2}{*}{ VLBI/VieVS-WVR } & - & - & $0.49(0.00)$ & $0.31(0.00)$ & - & - & - & - & - & - & - \\
\hline & - & - & $0.57(0.00)$ & $0.11(0.14)$ & - & - & - & - & - & - & - \\
\hline \multirow[t]{2}{*}{ VLBI/VieVS-ECMWF } & $0.62(0.00)$ & $0.51(0.00)$ & $0.52(0.00)$ & $0.51(0.00)$ & $0.28(0.03)$ & $0.17(0.20)$ & $0.74(0.00)$ & $0.40(0.00)$ & $0.01(0.94)$ & $0.24(0.06)$ & $0.34(0.04)$ \\
\hline & $0.61(0.00)$ & $0.21(0.10)$ & $0.76(0.00)$ & $0.31(0.02)$ & $0.48(0.00)$ & $0.42(0.00)$ & $0.51(0.00)$ & $0.28(0.03)$ & $0.10(0.43)$ & $0.14(0.28)$ & $0.60(0.00)$ \\
\hline \multirow[t]{2}{*}{ VLBI/VieVS-JMA/KARAT } & - & - & - & - & - & - & - & $0.39(0.00)$ & - & - & - \\
\hline & - & - & - & . & - & - & - & $0.50(0.00)$ & - & - & - \\
\hline \multirow[t]{2}{*}{ VLBI/VieVS-CreSS } & - & - & - & - & - & - & - & $0.45(0.00)$ & - & - & - \\
\hline & - & - & - & - & - & - & - & $0.41(0.00)$ & - & - & - \\
\hline
\end{tabular}

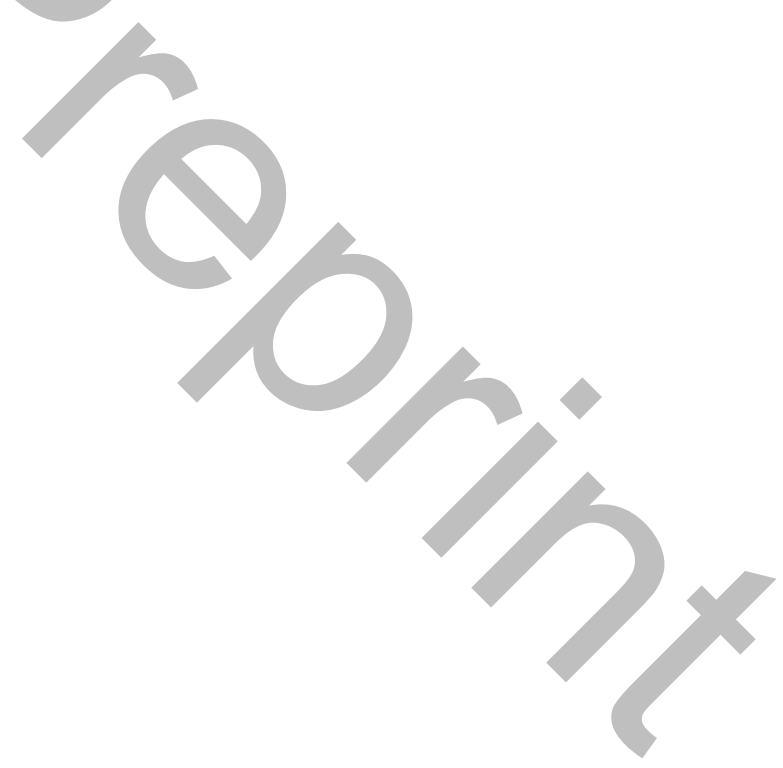




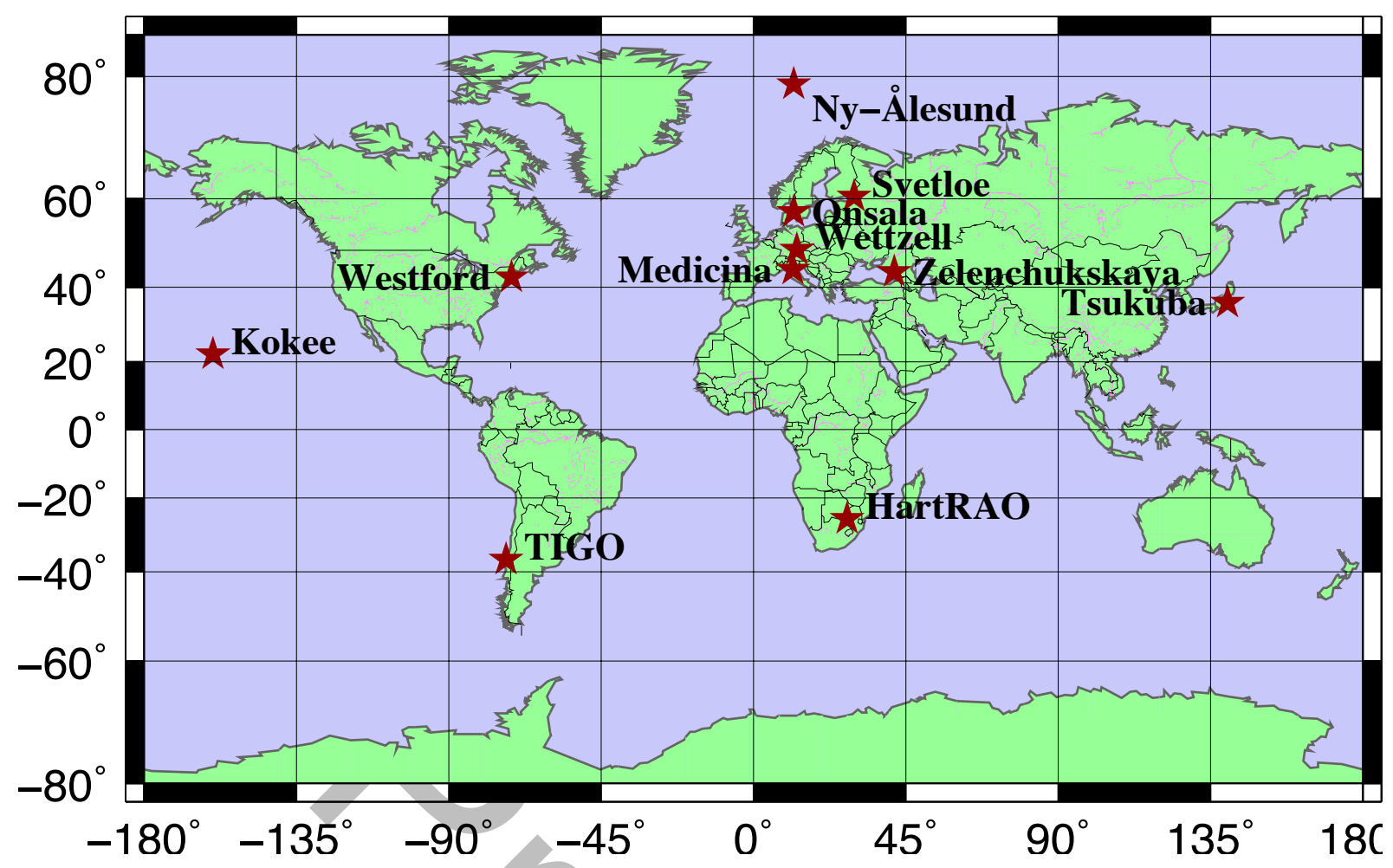

Figure 1 IVS CONT08 stations. 


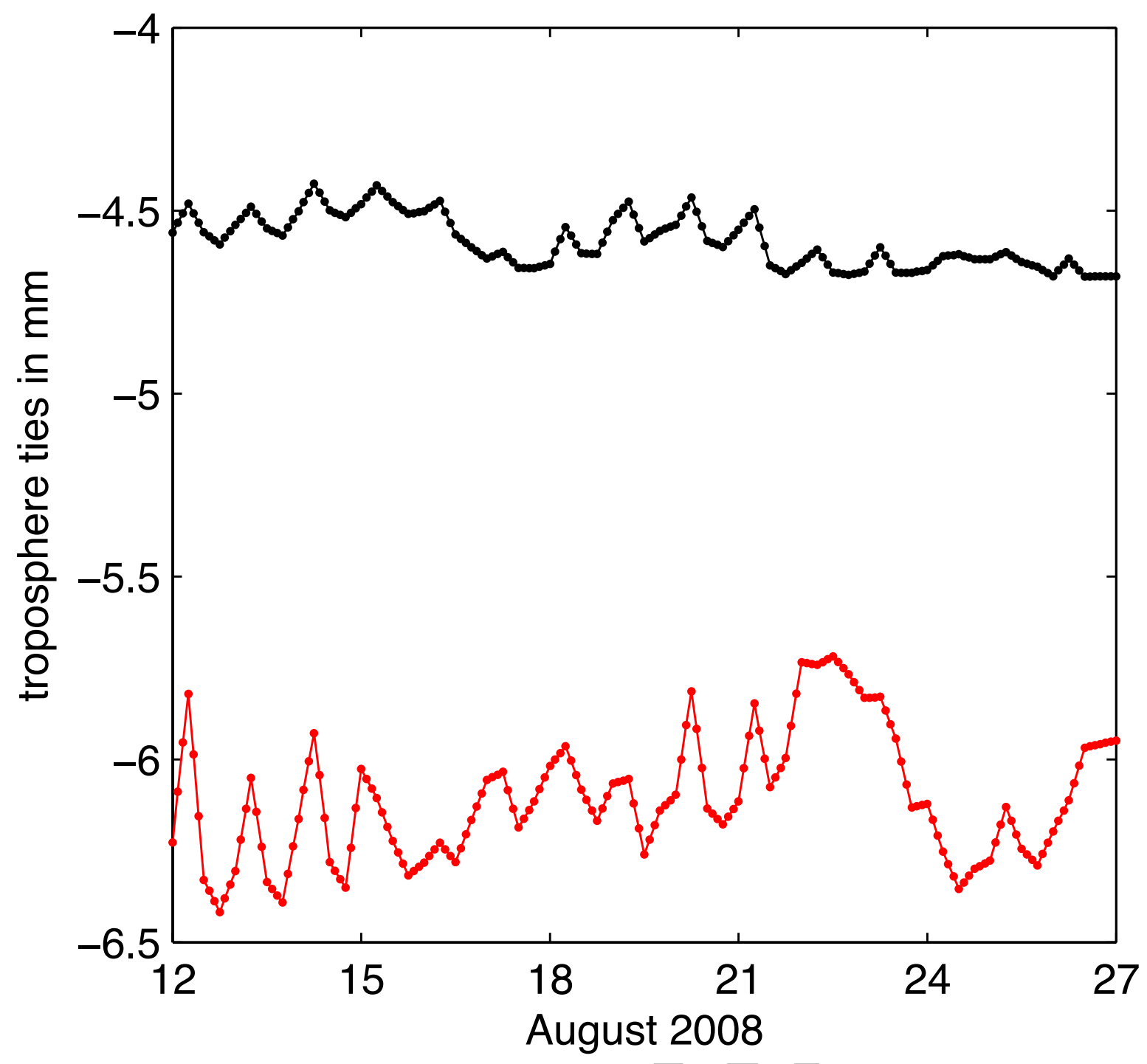

Figure 2 Troposphere ties between the GPS antenna TSKB and the VLBI antenna TSUKUB32 during CONT08, calculated for all common epochs. Red and black dotted lines illustrate total and hydrostatic ties, respectively. 


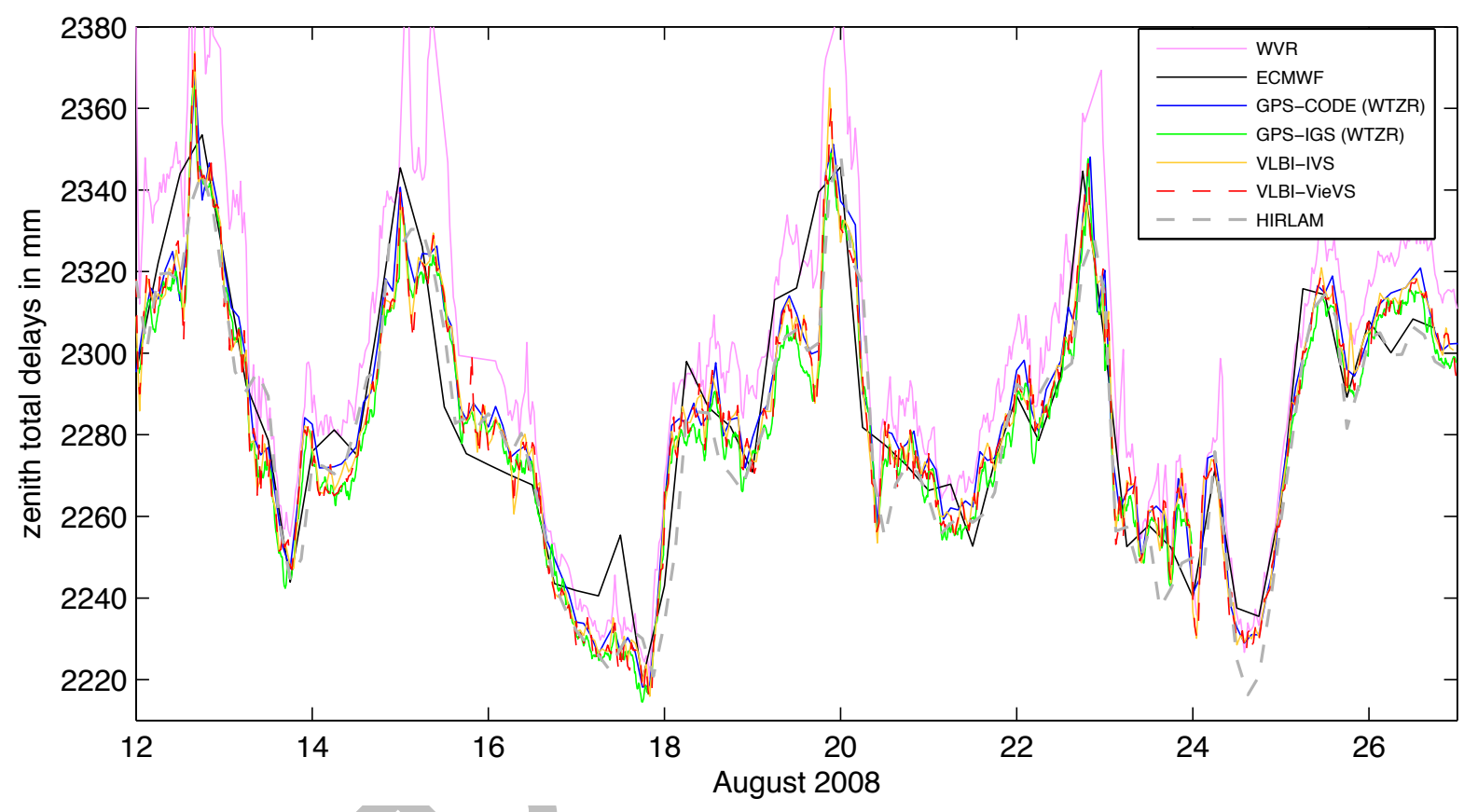

Figure 3 Troposphere ZTDs of the co-located site Wettzell during CONT08. 


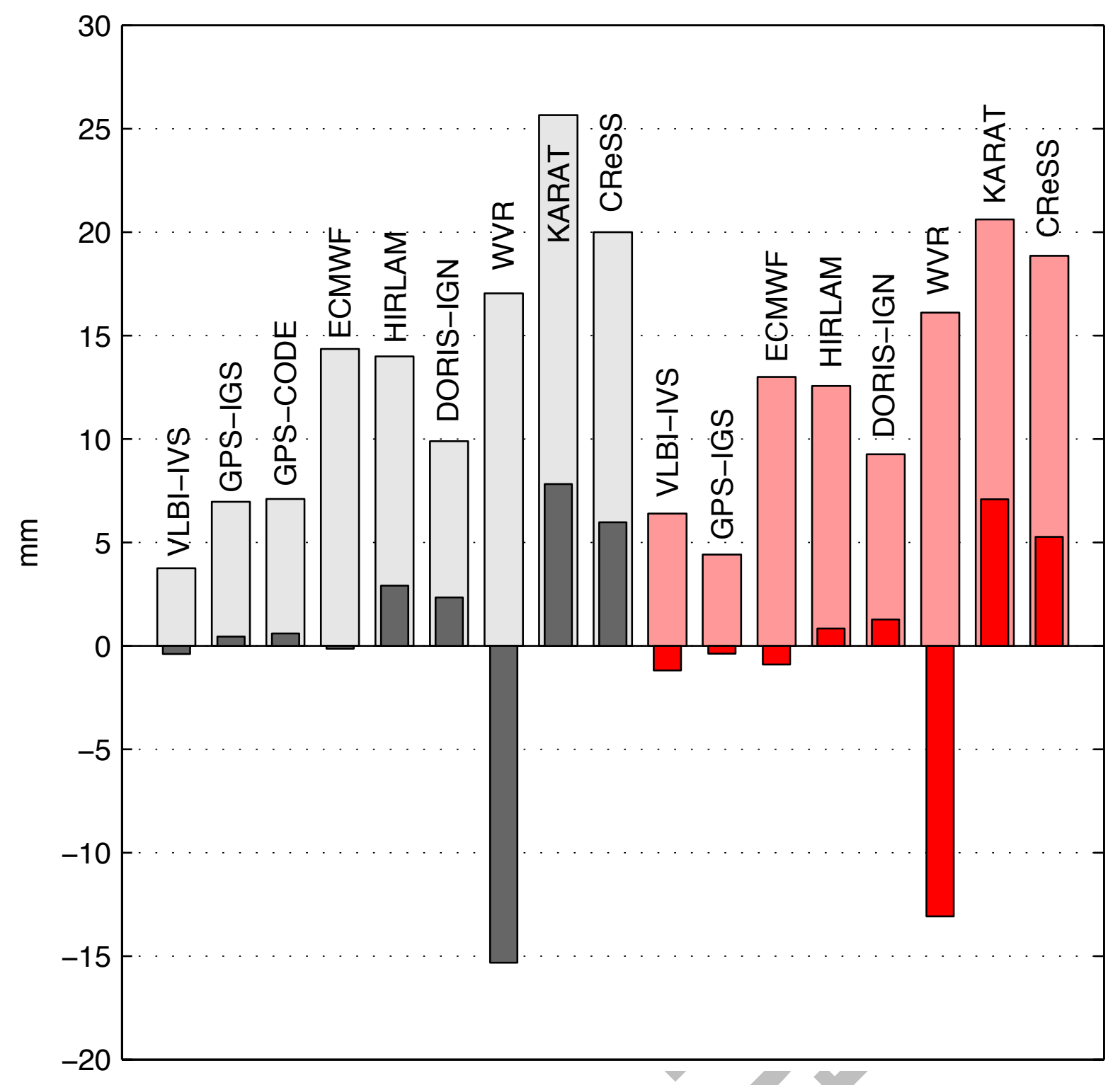

Figure 4 Mean biases and standard deviations of all ZTDs during CONT08 w.r.t. VLBI-VieVS (bias: dark grey, std. dev.: light grey) and GPS-CODE (bias: dark red, std. dev.: light red). 


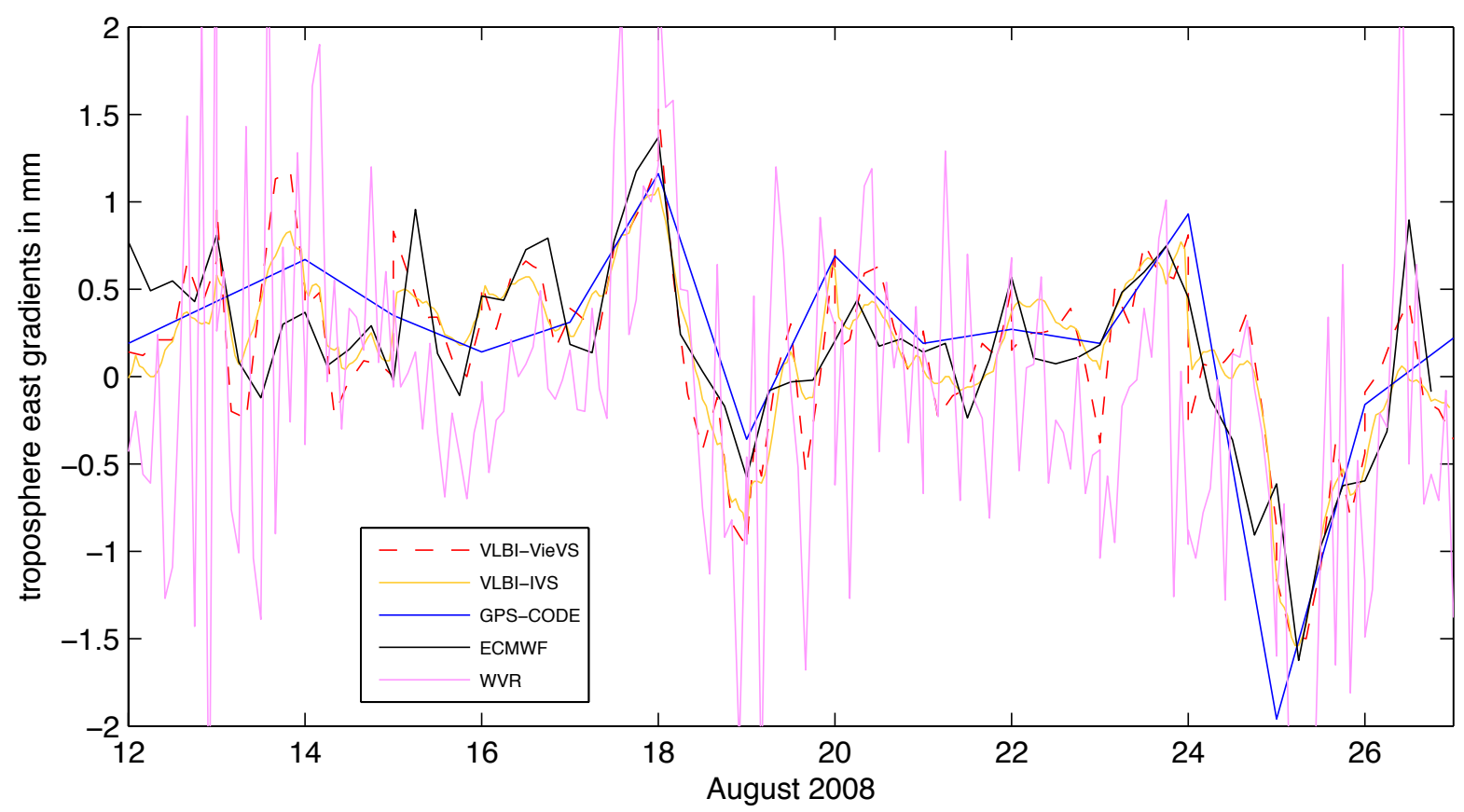

Figure 5 Troposphere east gradients of the co-located site Onsala during CONT08. 